\title{
Aprendiendo de una transformación de prácticas pedagógicas en cursos de maestría en la modalidad híbrida de aprendizaje
}

\section{Learning from a transformation of pedagogical practices in master's degree courses in the hybrid mode of learning}

\author{
Álvaro Hernán Galvis \\ Universidad de los Andes, Bogotá, Colombia \\ a.galvis73@uniandes.edu.co \\ Yelenis Yanit López González, \\ Universidad de La Guajira, Riohacha, Colombia \\ yelenislopez@uniguajira.edu.co \\ Marlin Alicia Aarón Gonzálvez \\ Universidad de La Guajira, Riohacha, Colombia \\ maaron@uniguajira.edu.co
}

\begin{abstract}
Resumen
Este documento comparte una reflexión crítica acerca de la motivación, desarrollo y resultados derivados de una transformación pedagógica de un curso de la MPTIC-Maestría en Pedagogía de las TIC - Tecnologías de Información y Comunicación-de la Universidad de La Guajira, en Riohacha, Colombia. Este estudio puede ser de interés para quienes desean ofrecer entornos flexibles de aprendizaje a adultos que necesitan cursar formación avanzada en instituciones donde se desea aplicar el constructivismo social apoyado en uso de TIC y donde no necesariamente hay un único modelo educativo ni operativo para ofrecer educación en modalidad combinada de aprendizaje-blended learning. Manteniendo lo esencial de la metodología de seminario que orienta a la MPTIC y la multi-dimensionalidad que asume la modalidad híbrida de aprendizaje en esta maestría, se llevó a cabo el rediseño y prueba del segundo nivel del seminario de Didáctica Aplicada, con estudiantes de la tercera cohorte del programa, donde los actores eran los mismos que en el primer nivel, pero se ajustó el modelo operativo del curso, para superar las limitaciones que se encontraron al llevar a cabo el primer nivel. Esto se hizo con la intención de buscar participación más activa, individual y grupal, así como lograr mejores resultados cualitativos en la aplicación de lo aprendido a los entornos de docencia en que hacen su proyecto de profundización. Con este estudio se buscó determinar qué lecciones deja esta transformación pedagógica, de cara a su posible réplica en otros cursos de la MPTIC y/o en contextos y por otros actores de programas de formación avanzada que están al servicio de personas que trabajan y estudian y que requieren hacer uso de ambientes flexibles de aprendizaje. El estudio deja a consideración lecciones aprendidas y recomendaciones.
\end{abstract}

Palabras claves

Aula invertida, blended learning, facilitación desde el lado, modalidad híbrida de aprendizaje, foros virtuales constructivistas, evaluación auténtica, transformación pedagógica. 


\begin{abstract}
This document shares a critical reflection on the motivation, development and results derived from a pedagogical transformation of a course of the MPTIC-Masters in Pedagogy of ICTInformation and Communication Technologies-University of La Guajira, in Riohacha, Colombia. This study may be of interest to those who wish to offer flexible learning environments to adults who require to pursue advanced training in institutions where they believe in technology-based socio-constructivism and where not necessarily there is a single educational and operational model to offer learning opportunities. Keeping the essence of the seminar methodology that guides the MPTIC and the multi-dimensionality that assumes the hybrid learning modality in this master's degree program, it was conducted the redesign and testing of the second level of a seminar offered to one of the cohorts of the MPTIC. In this process the actors were the same as in the first level- the same students participated, were guided by the same faculty members, and were accompanied by the same managers, but the operational model of the second level of the course of interest was adjusted to overcome some of the limitations found out in the implementation of the first level course. This had the intention of seeking more active participation at individual and group level, as well as to achieve better qualitative results in the application of what has been learned to the teaching environments in which the participants of the MPTIC do their deepening projects. This study sought to determine what lessons this pedagogical transformation leaves, in the face of its possible replication in other courses of the MPTIC and / or in contexts and by other actors of advanced training programs at the service of people who work and study, and who require making use of flexible learning environments. The work leaves to consideration lessons learned and recommendations.

\section{Keywords}

Authentic assessment, blended learning, constructivist virtual forums, facilitation from the side, flipped classroom methodology, hybrid learning mode, transformation of pedagogical practices.
\end{abstract}

\title{
1. Contexto educativo del estudio
}

La Maestría en Pedagogía de las TIC_-MPTIC — de la Universidad de la Guajira inicia su vida formativa en el año 2012 y se ofrece en modalidad semi-presencial desde la sede de Riohacha, en La Guajira, Colombia, a la comunidad de educadores de la región Caribe colombiana. Es una maestría profesionalizante, al servicio de la cualificación de docentes en ejercicio de cualquier disciplina profesional y/o a cualquier nivel educativo. La MPTIC busca posibilitar en sus beneficiarios competencias para el desarrollo, análisis y transformación de sus prácticas pedagógicas con el uso y apropiación de las tecnologías de la información y la comunicación (TIC) en las instituciones educativas en donde laboren (UNIGUAJIRA - MOTIVAR, 2010).

\subsection{Liderazgo académico en la MPTIC}

Desde esta apuesta y compromiso, la MPTIC promueve estrategias para la enseñanza en sus escenarios formativos que son orientadas desde el grupo de investigación que coordina la maestría - Grupo Motivar, de Uniguajira-y son puestas en marcha por los docentes que participan; algunos de ellos de planta o catedráticos de la Uniguajira, así como profesores invitados, externos.

Para cada escenario formativo, la coordinación de la maestría presenta al académico que ha sido seleccionado para orientarlo (docente titular), las intenciones del seminario a cargo, los objetivos de aprendizaje que se pretenden lograr y los aprendizajes previos con que se espera cuenten los estudiantes a partir de los seminarios ya cursados. La

Aprendiendo de una transformación de prácticas pedagógicas en cursos de maestría en la modalidad híbrida de aprendizaje. Álvaro Hernán Galvis, Yelenis Yanit López González y Marlín Alicia Aarón Gonzálvez. 
Coordinación Académica valora las propuestas tecno-pedagógicas que los profesores elaboran, les da información de retorno para ajustar lo que sea conveniente y en compañía de ellos a lo largo del proceso, hace análisis del mismo en el aula física y en los espacios virtuales.

\subsection{Modelo educativo de la MPTIC.}

El diseño curricular de la MPTIC propone un plan de estudio con núcleo central en diseño pedagógico apoyado en uso de tecnología digital y con fundamentación teórica y metodológica centrada en la pedagogía activa e investigación aplicada, dentro de un enfoque constructivista social; reconoce espacios de formación en contexto real y académico, en entornos presenciales y virtuales que sirvan para el mejoramiento y transformación del quehacer docente de los participantes; se busca que las TIC puedan contribuir en esta transformación.

Una de las intenciones de la maestría asociada a todo su plan curricular, es que los estudiantes, además de avanzar en saberes tecno-pedagógico e investigativo, mejoren su competencia para gestionar información, analizarla, generar y comunicar nuevas ideas; en este sentido se le pide a cada docente, que las propicie dentro de su accionar pedagógico.

La invitación a todos los docentes de la MPTIC es que hagan uso de pedagogías activas -centradas en la construcción de conocimiento a partir de actividad de los estudiantes y/o de los grupos-, que favorezcan el pensamiento crítico, que se planeen didácticas desde la perspectiva socio-constructivista y preferiblemente usando aula invertida, que evalúen los aprendizajes en función de lo propuesto y realizado, diferenciando logros individuales de los colaborativos, y que todos los seminarios tributen para ayudar a los estudiantes a consolidar su Proyecto de Profundización.

En consonancia con estas estrategias y orientaciones para los docentes, en paralelo, se invita a los estudiantes de manera permanente a atender las propuestas pedagógicas de los docentes, a responder al ritmo y lógica que los docentes proponen y a desarrollar ejercicios previos a las sesiones de cada seminario que les ayuden a estar al día con las acciones formativas que se generan en ellos.

\subsection{Modelo operativo de la MPTIC.}

La MPTIC se desarrolla por semestres (4) en modalidad híbrida, con metodología activa puesta en práctica con la estrategia de seminarios que combinan sesiones presenciales todos los fines de semana con trabajo virtual de docentes y estudiantes durante la semana, aprovechando las bondades de cada uno de estos entornos para llegar al conocimiento (Aarón, Choles, \& Cuesta, 2017). Este modelo operativo da libertad para que el docente lo instrumente de la manera que mejor se acomode a lo que enseña y a las estrategias de aprendizaje que considere más pertinentes a las competencias que desea favorecer, en atención a lo definido en el modelo educativo de cada seminario a su cargo.

Aprendiendo de una transformación de prácticas pedagógicas en cursos de maestría en la modalidad híbrida de aprendizaje. Álvaro Hernán Galvis, Yelenis Yanit López González y Marlín Alicia Aarón Gonzálvez. 


\subsection{Seguimiento reflexivo}

Una estrategia de mejoramiento en la Maestría en PTIC y de investigación desde la IAP - Investigación Acción Participativa, es la participación y seguimiento permanente por parte de la coordinación y del Comité Académico a todos los procesos formativos que se gestan en ella. Esto tiene la intención de aprender mediante reflexión de buenas y no tan buenas prácticas, propiciando su permanencia cuando convenga, o su mejoramiento y uso por parte del colectivo docente. Este seguimiento se hace a las pedagogías y estrategias didácticas que se ponen en marcha, así como a los Entornos Tecnológicos de Apoyo-ETA, que son herramientas tecnológicas, identificadas como mediaciones que sirven y ayudan a la enseñanza, que se usan en las sesiones presenciales y virtuales.

\subsection{Ciclos de mejoramiento}

La coordinación de la MPTIC, en un ejercicio dialógico y permanente con sus docentes, desarrolla un continuo seguimiento a las interacciones que se dan en las sesiones presenciales y virtuales, haciendo eco a las evaluaciones de las jornadas, genera un círculo virtuoso, que busca reconocer si se están generando al interior de sus espacios formativos, los aprendizajes que se pretenden a cargo de las didácticas que ponen en marcha sus docentes. Favorecerlos es su responsabilidad, y por ello todo el equipo se dispone a validar las estrategias.

N.B. Los conceptos usados en este estudio se definen en el apéndice 1

\section{Diseño y transformación pedagógica de los seminarios de Didáctica Aplicada en la MPTIC}

Uno de los ejes de formación de la MPTIC es el de Modelos Pedagógicos y TIC. Con él se busca que los participantes desarrollen criterio respecto a lo que conlleva hacer uso educativo de TIC para implementar modelos pedagógicos relevantes a lo que y a quienes se desea apoyar en el proceso de aprendizaje (UNIGUAJIRA - MOTIVAR, 2010). Dentro de este contexto, la coordinación de la MPTIC invitó al profesor Álvaro Hernán Galvis, de la Universidad de los Andes, a proponer dos seminarios de tres créditos cada uno, que hiciesen uso de los modelos educativos y operativos antes mencionados para la MPTIC, con el fin de sentar las bases conceptuales e instrumentar las grandes ideas (conceptos fundamentales) de la didáctica aplicada con apoyo de TIC.

\subsection{Participantes en los seminarios de Didáctica Aplicada 1 y 2}

Los seminarios se diseñaron tomando en cuenta que sus estudiantes son docentes en ejercicio en diversidad de disciplinas y niveles, algunos con formación pedagógica, otros sin ella; la gran mayoría de ellos alfabetas informáticos y con diversidad de niveles de uso pedagógico de las TIC, desde el más bajo y ninguno con el más alto. Este contexto es importante para los seminarios de didáctica aplicada, dada la intención de la MPTIC de contribuir a la transformación de las prácticas pedagógicas de sus participantes en las instituciones en que laboran. Los aprendizajes y experiencias previos acerca de docencia, y el campo vital de cada quien en este dominio, según lo relieva la Gestalt (Lewin, 1939), no son solamente los contextos que pueden hacer

Aprendiendo de una transformación de prácticas pedagógicas en cursos de maestría en la modalidad híbrida de aprendizaje. Álvaro Hernán Galvis, Yelenis Yanit López González y Marlín Alicia Aarón Gonzálvez. 
significante el nuevo aprendizaje; en casos como este, donde predominantemente se hace docencia sobre base empírica y con variedad de sustentaciones pedagógicas, este contexto puede llegar a ser un facilitador de la transformación pedagógica, o un obstáculo, cuando al tratar de poner en práctica el modelo educativo con pedagogía activa apoyada en uso de TIC que propicia la MPTIC (UNIGUAJIRA - MOTIVAR, 2010) sacan de su zona de confort lo que saben y hacen los educadores que hacen parte de la maestría como estudiantes. No es de extrañar que la transformación pedagógica de los participantes como docentes exija desaprender y (re)aprender conceptos, procedimientos y herramientas con el fin de lograr visiones educativas que sean deseables de alcanzar (Restrepo Gómez, 2004, págs. 51-52).

\subsection{Actores del proceso}

De los 25 estudiantes de la tercera cohorte de la MPTIC, 20 personas tomaron parte en estos seminarios, todas ellas docentes en instituciones de la región caribe colombiana. El primer nivel del seminario lo cursaron en 2016-2, cuando estaban en segundo semestre de la maestría, y el segundo nivel, en 2017-1. La dirección del curso y facilitación de la interacción en entorno presencial estuvo a cargo de Álvaro Hernàn Galvis (docente titular), el acompañamiento al proceso de aprendizaje en entorno virtual estuvo al cuidado de Yelenis López (docente auxiliar); cada uno de ellos también llevó a cabo la función de evaluación formativa y sumativa del componente a su cargo. El acompañamiento al proceso de enseñanza y evaluación fue realizado por las profesoras Rosalba Cuesta y Marlin Aarón, ambas miembros del Grupo Motivar - Coordinadora de MPTIC y miembro del comité académico de la MPTIC, respectivamente, quienes estuvieron a cargo de la observación participante y el seguimiento a las sesiones presenciales e interlocución con los actores durante todo durante el proceso formativo.

\subsection{Diseño educativo de los seminarios de didáctica aplicada}

El diseño educativo propuesto para los dos niveles de los seminarios se sintetiza en los Apéndices 2 y 3. Ambos diseños buscan ser un ejemplo de lo que significa idear ambientes de aprendizaje siguiendo la metodología de Grandes Ideas (Wiggins \& McTighe, 2005) (Mitchell, Keast, Panizzon, \& Mitchell, 2017), metodología que estos seminarios proponen que conozcan y valoren los participantes en la MPTIC y, si es del caso, la apropien para la transformación pedagógica de sus procesos de docencia. El Apéndice 2 muestra que el nivel 1 del seminario de Didáctica Aplicada se centra en propiciar apropiación de aportes de los enfoques educativos heurístico y algorítmico (Galvis, 2010), así como de las teorías de aprendizaje conductistas, cognitivistas y conectivistas, al diseño de ambientes de aprendizaje apoyados con TIC (Galvis, 2012). El Apéndice 3 muestra que el segundo nivel del seminario se centra en entender por qué y cómo hacer diseño de ambientes de aprendizaje por enfoque de grandes ideas, con evaluaciones auténticas, pedagogía activa y con apoyo de TIC (Galvis, 2007) (Galvis \& Pedraza, 2012).

Estos diseños siguen los mismos patrones de pedagogía activa que propone la MPTIC, centrada en indagación individual y colaboración entre pares (ver interrogantes esenciales en cada diseño) con miras a apropiar conceptos fundamentales (ver gran idea de cada seminario) que se apliquen al contexto de docencia en que cada estudiante se

Aprendiendo de una transformación de prácticas pedagógicas en cursos de maestría en la modalidad híbrida de aprendizaje. Álvaro Hernán Galvis, Yelenis Yanit López González y Marlín Alicia Aarón Gonzálvez. 
desempeña. Los resultados observables asociados a cada gran idea piden aplicar lo aprendido a problemas auténticos (del contexto real de los participantes) y las rúbricas que se proponen para auto-evaluación, co-evaluación y hetero-evaluación, buscan apalancar el auto-control creciente de los aprendices. Los hallazgos de la construcción colaborativa de conocimiento y de las propuestas de solución a tareas auténticas relevantes, buscan lograr entendimiento perdurable de las grandes ideas enunciadas por nivel. Al hacer esto en entornos flexibles de aprendizaje apoyados en tecnología digital, se busca que haya vivencias de las que se aprende, tanto en modalidad presencial como virtual.

\subsection{Fundamentación de los seminarios de didáctica}

Ambos seminarios hacen uso de ambientes híbridos de aprendizaje multidimensionales (Rossett \& Frasee, 2006) (Osorio Gómez \& Duart, 2012) (Galvis, 2017A) en los que combinan selectivamente entornos presenciales y virtuales de aprendizaje con recursos transmisivos, activos y colaborativos (Forté \& Wentland, 1998). Como se mencionó antes, siguen diseño por grandes ideas (Wiggins \& McTighe, 2005) (Mitchell, Keast, Panizzon, \& Mitchell, 2017) y toman en cuenta resultados de estudios acerca de interacción en ambientes virtuales (Collison, Elbaum, Haavind, \& Tinker, 2002) y en ambientes híbridos de aprendizaje (Osorio Gómez, 2011), pedagogía activa (Pérez Serrano, 2006) usando aula invertida (ITESM, 2014), transformación de ambientes educativos para hacer uso de pedagogía activa (The National Center for Academic Transformation, 2005), de buenas prácticas en el uso de tecnología en educación (Bates, 2015), así como de eLearning y bLearning en educación superior (Galvis \& Pedraza, 2013) (Galvis, 2017B).

\subsection{Implementación del diseño del seminario de nivel 1}

La primera implementación siguió lo que hasta el momento era un estándar en MPTIC: Los alumnos dedican el fin de semana en el aula TIC de la Universidad de La Guajira a interactuar con el docente y con sus compañeros en la apropiación de modelos mentales que propone el docente, combinando exposiciones con discusiones y ejercicios aplicativos; durante el resto de la semana los estudiantes hacen por su cuenta trabajos de profundización y aplicación de lo aprendido y entregan tareas o proyectos que sirvan de base para dar retroalimentación y nota.

\subsubsection{Modelo operativo del nivel 1, en la teoría y en la práctica}

La Figura 1 muestra el modelo operativo que se propuso para el primer nivel del seminario de Didáctica Aplicada, en el que se suponía que los participantes tenían experiencia en bLearning, pues era su segundo semestre y en los diversos seminarios de la MPTIC se venía aplicando. El modelo es del tipo pedagogía invertida, propone que, mediante estudio independiente, los participantes apropien los contenidos de los recursos digitales puestos a su disposición antes de la sesión presencial y en ésta, se haga profundización e ilación de saberes.

La realidad mostró que solo unos pocos de los participantes llegaron a la primera sesión presencial con el material estudiado y que los entregables pedidos, por consiguiente, no estaban listos para co-evaluación en la misma. Frente a esto, se decidió ajustar la

Aprendiendo de una transformación de prácticas pedagógicas en cursos de maestría en la modalidad híbrida de aprendizaje. Álvaro Hernán Galvis, Yelenis Yanit López González y Marlín Alicia Aarón Gonzálvez. 
estrategia pedagógica para la primera sesión presencial propiciando que en la primera parte de la jornada cada quien hiciera explícitas sus respuestas al primer grupo de interrogantes esenciales (IE1.1, ver Apéndice 2) y, a partir de diálogo socrático con el director del curso, analizaran dichas prácticas desde la perspectiva de los enfoques algorítmico y heurístico (Galvis, 2010). Para la segunda sesión, al día siguiente, se hizo división de responsabilidades entre los participantes y se asignaron al azar en seis grupos para hacer lectura individual detallada y posterior discusión de los conceptos y principios para aplicación de cada una de las teorías de aprendizaje propuestas (Galvis, 2012). Sobre esta base, cada grupo socializó en plenaria sus hallazgos. Sobre el panorama de conceptos y principios de las distintas teorías, se volvió sobre las respuestas a los IE 1.1 y se pidió a cada quien tratar de hallar una primera respuesta al IE1.3, lo cual sirvió de base para una discusión en gran grupo acerca de lo que son prácticas pedagógicas sustentadas en una u otra teoría.

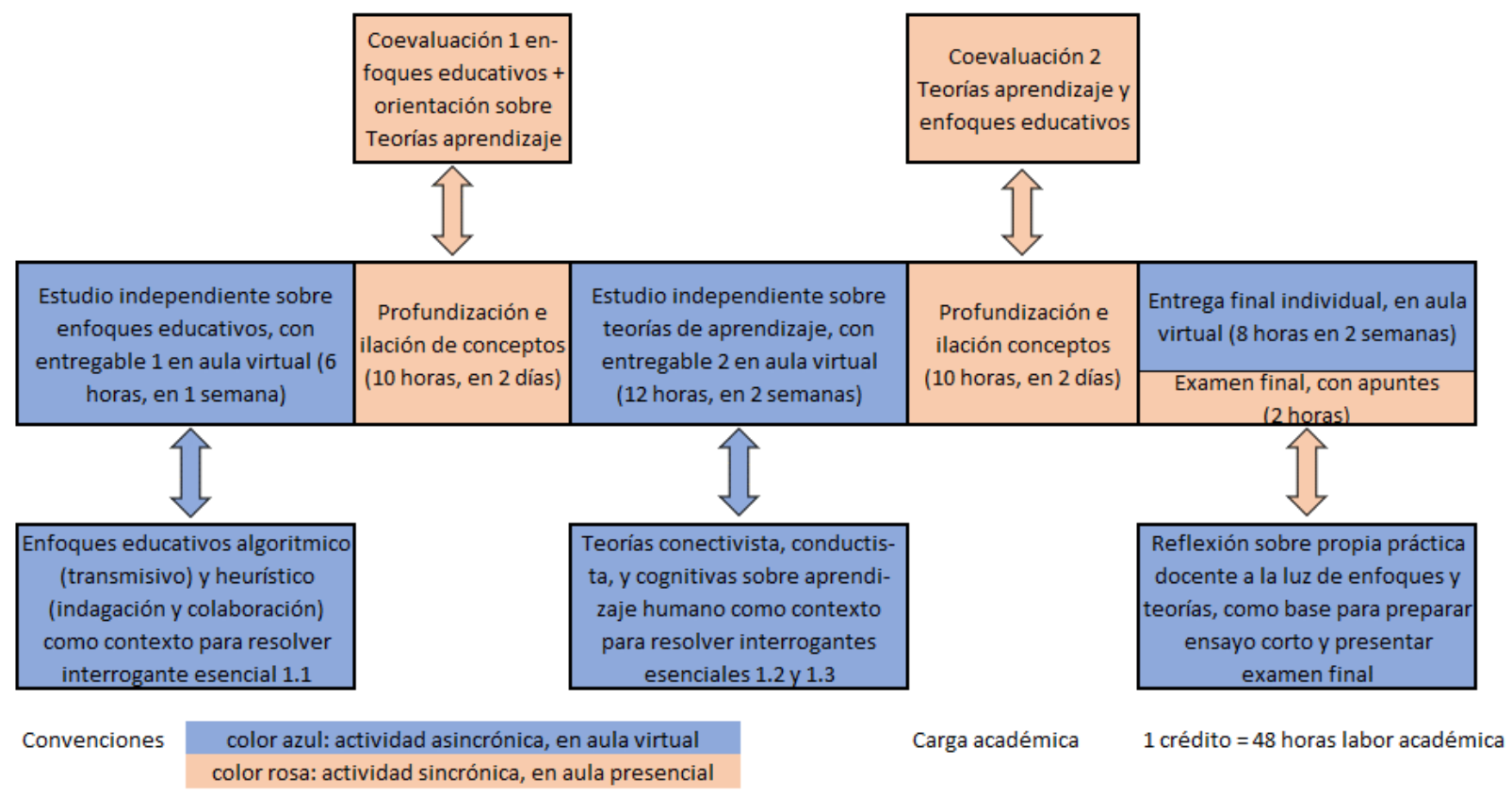

Figura 1. Modelo operativo para el Seminario de Didáctica Aplicada 1 en la MPTIC, cohorte III, fuente: A Galvis

El estudio independiente inter-presencial se esperaba que fluyera según lo esperado, es decir, que los participantes dedicaran en promedio seis horas por semana durante dos semanas a leer, analizar y aplicar lo aprendido a la solución de los IE 1.2 y 1.3, para aportar como insumo a la segunda sesión presencial los segundos entregables. Aunque el nivel de preparación con que llegaron a la sesión de profundización fue mayor que en la primera presencial, los trabajos sobre los IE 1.2 y 1.3 tuvieron muy diverso nivel de logro, siendo muy valioso el ejercicio de co-evaluación, en el que cada pareja se dio información de retorno e identificó conceptos que necesitaban afinamiento. Esto se hizo en la sesión plenaria, donde el profesor titular usó de nuevo método socrático para propiciar que se clarificaran los conceptos.

Aprendiendo de una transformación de prácticas pedagógicas en cursos de maestría en la modalidad híbrida de aprendizaje. Álvaro Hernán Galvis, Yelenis Yanit López González y Marlín Alicia Aarón Gonzálvez. 


\subsubsection{Resultados e información de retorno}

Los participantes tuvieron dos semanas para hacer entrega individual en el aula virtual de lo pedido en el RO1 (ver Apéndice 2), con posibilidad de auto-evaluarse haciendo uso de la rúbrica 1. Al final de este período presentaron en aula TIC un examen escrito hasta de 2 horas, con posibilidad de consultar sus apuntes manuscritos; el examen constó de diez situaciones auténticas que ellos debían valorar si aplicaban los conceptos mencionados en RO1, sustentando.

La tabla 1 muestra los resultados de aprendizaje, los cuales muestran que 3 de 20 personas no entregaron su ensayo pero que todos presentaron el examen; los niveles de reprobación, con $70 \%$ o menos de los puntos posibles, son mayores en el ensayo que en el examen y definitivo, siendo el nivel de logro en el ensayo lo que más incidió en esto. Mientras que en el examen la gran mayoría aprobó con $80 \%$ o más de lo esperado, en el ensayo y en la nota definitiva, solo alrededor del $40 \%$ lo logró. Cabe señalar que ambas instancias de evaluación usaron pruebas auténticas, en un caso relativas a lo que cada quien hace en su práctica docente y en otro relativas a mini-casos (situaciones) reales. También es importante mencionar que hubo flexibilidad en los tiempos de entrega del ensayo, para atender limitaciones que documentaron algunos de los estudiantes.

Tabla 1. Resultados académicos en Seminario de Didáctica 1, 2016-2, cohorte III

\begin{tabular}{|l|c|c|c|}
\hline Seminario de Didáctica aplicada I, 2016-2 & $\begin{array}{c}\text { Ensayo 1 } \\
\text { (hasta 3 puntos) }\end{array}$ & $\begin{array}{c}\text { Examen 1 } \\
\text { (hasta 2 puntos) }\end{array}$ & $\begin{array}{c}\text { Nota Definitiva } \\
\text { (hasta 5 puntos) }\end{array}$ \\
\hline Participantes que entregaron lo pedido & 17 & 20 & 20 \\
\hline Reprobaron, con menos de 70\% logro & $29.41 \%$ & $5.00 \%$ & $20.00 \%$ \\
\hline Aprobaron con 70\% o más, y menos de 80\% & $29.41 \%$ & $25.00 \%$ & $40.00 \%$ \\
\hline Aprobaron con 80\% o más de logro & $41.18 \%$ & $70.00 \%$ & $40.00 \%$ \\
\hline
\end{tabular}

Al final de cada seminario se pidió a los participantes dar respuesta a un formulario de información de retorno. Diecinueve de 20 personas lo respondieron luego de las dos sesiones presenciales; en ambas ocasiones, por unanimidad dijeron que el seminario, su metodología y contenidos eran excelentes. En los comentarios expresaron su satisfacción por el diseño, implementación, materiales, manejo de aula del profesor titular y acompañamiento fuera de aula por parte del docente auxiliar. Pidieron tener en cuenta que no todos son docentes de trayectoria y que a algunos les cuesta captar el sentido de los términos que se usan, lo cual les impide aplicarlos en su contexto.

\subsubsection{Valoración de logros y retos en el seminario de didáctica I}

Los profesores a cargo del seminario, así como quienes participan como observadores del ciclo de mejoramiento del MPTIC coincidieron en que este modelo operativo mostró que funcionaba hasta cierto punto, pues por falta de preparación de buen número de estudiantes en el trabajo previo a las sesiones presenciales, estas no fueron suficientes para ir a profundidad en lo deseado, siendo necesario que esto y los trabajos prácticos quedaran para después de cada presencial.

Aprendiendo de una transformación de prácticas pedagógicas en cursos de maestría en la modalidad híbrida de aprendizaje. Álvaro Hernán Galvis, Yelenis Yanit López González y Marlín Alicia Aarón Gonzálvez. 
La calidad de los trabajos que llevaron a las presenciales y los que entregaron al final del proceso fue muy diversa, así como también la oportunidad de su entrega; hubo que ser muy flexibles en esto, dado que se sobrelaparon actividades del seminario con algunas que respondían a exigencias de los varios docentes del programa y otras a responsabilidades que como individuos tienen los estudiantes de la MPTIC. Poco aprovechamiento se vio del intento de hacer aprendizaje invertido y autónomo.

El mayor defecto de este modelo operativo fue el desaprovechamiento del aprendizaje autónomo, pues al no hacerse como era esperado, las actividades no presenciales poco fomentaron la capacidad de auto-aprendizaje, aunque sí la capacidad de auto-aplicación de lo aprendido. Se decidió para el segundo nivel de los mismos cursos mantener la modalidad híbrida con pedagogía invertida, pero con actividades previas que exigieran estudio individual y construcción colaborativa de conocimiento.

\subsection{Implementación del diseño del seminario de nivel 2}

El diseño educativo del seminario de nivel 2 se presenta en el Apéndice 3. Sigue la misma metodología que el del nivel 1, con diseño por grandes ideas como organizadoras, con resultados observables y evaluación auténtica como derrotero y con interrogantes esenciales como puentes para pasar del nivel de ingreso al esperado. Los ajustes grandes se hicieron en el modelo operativo, como se explica más adelante, hechos con la intención de buscar participación más activa, individual y grupal, así como lograr mejores resultados cualitativos en la aplicación de lo aprendido a los entornos de docencia en que los participantes hacen su proyecto de profundización.

\subsubsection{Investigación-acción educativa en los seminarios de didáctica}

Se decidió someter a prueba la tesis de que, manteniendo el diseño educativo original y la estrategia de modalidad híbrida y con aprendizaje invertido originales, al cambiar la dinámica de preparación a las sesiones presenciales, haciendo foros constructivistas virtuales y moderados por el docente, en vez de estudio independiente, era posible lograr mayor apropiación conceptual y en los trabajos de aplicación al caso propio, los cuales se inician en el Aula TIC durante las presenciales, con asesoramiento de los docentes y retroinformación entre pares, y culminan mediante trabajo guiado y en forma auto-gestionada.

Para lograr esto, se optó por hacer un estudio del tipo investigación-acción educativa, una forma de explorar una situación social (educativa) para mejorarla, en la que se encuentran como "indagadores" los implicados en la realidad investigada y cuyo objetivo es mejorar la calidad de la acción (Restrepo Gómez, y otros, 2011); la investigación-acción educativa es una herramienta que facilita la elaboración del saber pedagógico (Restrepo Gómez, 2004). Los participantes en el estudio fueron los estudiantes de la tercera cohorte de la MPTIC en Universidad de La Guajira (20 en el nivel 1, 19 en el nivel 2), los 2 docentes a cargo de los seminarios de Didáctica Aplicada, niveles 1 y 2 , y las 2 coordinadoras de la MPTIC que hacen seguimiento reflexivo a los seminarios.

Aprendiendo de una transformación de prácticas pedagógicas en cursos de maestría en la modalidad híbrida de aprendizaje. Álvaro Hernán Galvis, Yelenis Yanit López González y Marlín Alicia Aarón Gonzálvez. 


\subsubsection{Modelo operativo del nivel 2, en la teoría y en la práctica}

El diseño operativo sufrió importantes ajustes respecto al del primer nivel, como se aprecia en la Figura 2.

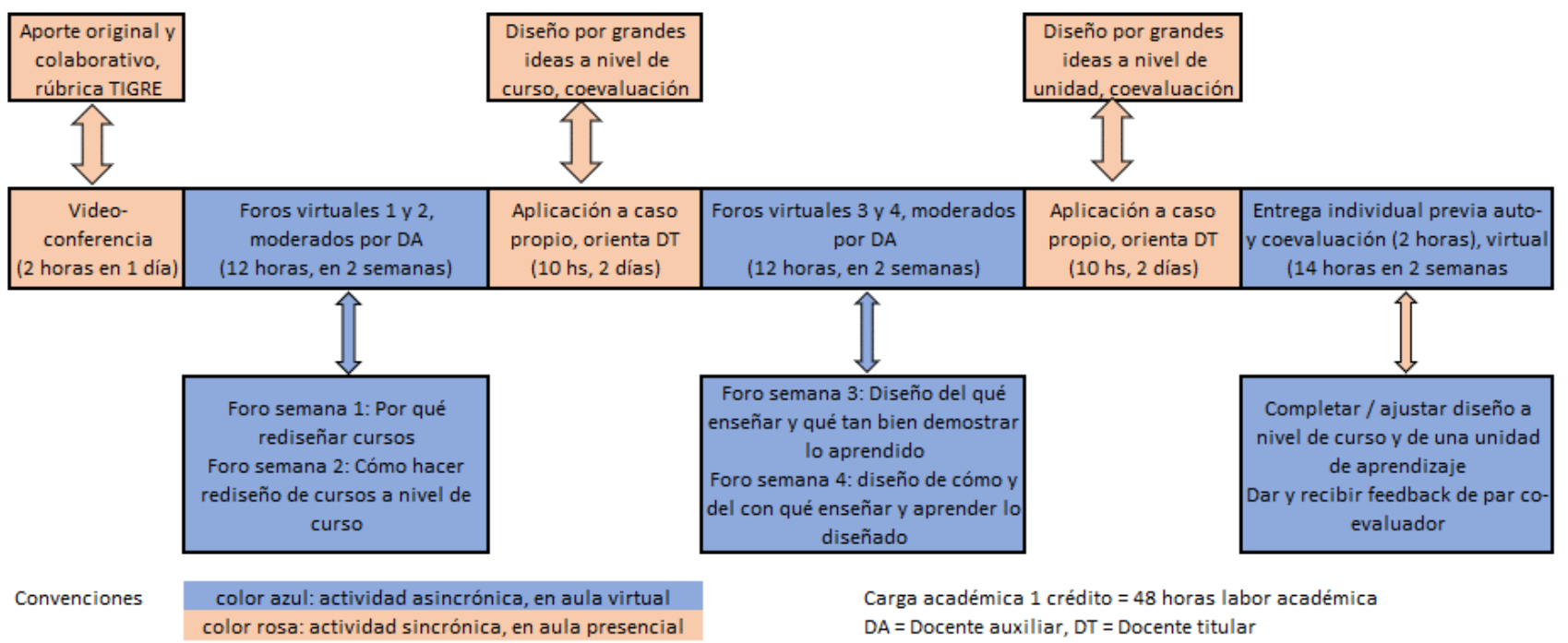

Figura 2. Modelo operativo para el Seminario de didáctica Aplicada 2 en la MPTIC, cohorte III. Fuente: A Galvis

Los cambios hechos responden al interés de propiciar trabajo autónomo que permita apropiar / interiorizar los conceptos que se van a aplicar en las sesiones presenciales, antes de éstas. Se optó por incluir foros virtuales semanales previos a las sesiones en Aula TIC, aplicando facilitación desde el lado (Collison, Elbaum, Haavind, \& Tinker, 2002) con moderación por parte de docente auxiliar y haciendo uso de la rúbrica TIGRE para auto-controlar y dar feedback sobre los aportes a los diálogos pragmáticos (Galvis, 2007).

También se decidió eliminar el examen final presencial que hubo en el nivel 1, toda vez que la participación en los foros es evidencia del entendimiento que cada quien tiene sobre los conceptos estudiados, con lo que el valor relativo de la nota final se distribuyó $50 \%$ en cada mitad del seminario, $30 \%$ a participación y logro en los foros y $20 \%$ a la calidad del trabajo práctico, a nivel de curso en la primera presencial y a nivel de una unidad en la segunda.

Quince días antes de la primera sesión presencial de este seminario se llevó a cabo una sesión virtual de 2 horas en la que cada participante, desde su equipo en Aula TIC, tuvo oportunidad de interactuar sincrónica y virtualmente con el docente titular y con sus compañeros, para discriminar entre lo que se considera un aporte original y uno colaborativo, y vivir experiencia directa aplicando la rúbrica TIGRE a sus aportes. Así mismo, se analizó la propuesta de trabajo de este segundo seminario donde se prevén 4 foros virtuales moderados, uno por semana, 2 antes de cada sesión presencial, para discutir el interrogante focalizador de la discusión de la semana. De este modo, el insumo a cada sesión presencial son los aportes a la discusión, y en las presenciales se

Aprendiendo de una transformación de prácticas pedagógicas en cursos de maestría en la modalidad híbrida de aprendizaje. Álvaro Hernán Galvis, Yelenis Yanit López González y Marlín Alicia Aarón Gonzálvez. 
hace aplicación de lo conceptualizado al caso propio, a nivel de curso en la primera presencial y a nivel de unidad en la segunda.

\subsubsection{Resultados e información de retorno}

La Tabla 2 visualiza los niveles de participación y logro en el Seminario de Didáctica 2. Como se aprecia, los 19 participantes inscritos tomaron parte en las distintas actividades, pero los niveles de rendimiento son variados.

Tabla 2. Resultados académicos en Seminario de didáctica 2, 2017-1, cohorte III

\begin{tabular}{|l|l|l|l|l|l|}
\hline $\begin{array}{l}\text { Seminario de didáctica } \\
\text { aplicada 2, 2017-1 }\end{array}$ & $\begin{array}{l}\text { Foros 1 y 2 } \\
\text { (hasta 5 } \\
\text { puntos, } \\
\text { 30\%) }\end{array}$ & $\begin{array}{l}\text { Diseño } \\
\text { macro (hasta } \\
\mathbf{5} \\
\text { puntos,20\%) }\end{array}$ & $\begin{array}{l}\text { Foros 3 y 4 } \\
\text { (hasta 5 } \\
\text { puntos, 30\%) }\end{array}$ & $\begin{array}{l}\text { Diseño unidad } \\
\text { (hasta 5 } \\
\text { puntos,20\%) }\end{array}$ & $\begin{array}{l}\text { Nota } \\
\text { definitiva } \\
\text { (hasta 5 } \\
\text { puntos) }\end{array}$ \\
\hline $\begin{array}{l}\text { Participantes que } \\
\text { entregaron lo pedido }\end{array}$ & 19 & 19 & 19 & 19 & 19 \\
\hline $\begin{array}{l}\text { Reprobaron, con menos } \\
\text { de 70\% logro }\end{array}$ & $31.58 \%$ & $10.53 \%$ & $36.84 \%$ & $42.11 \%$ & $21.05 \%$ \\
\hline $\begin{array}{l}\text { Aprobaron con 70\% o } \\
\text { más logro y menos de } \\
80 \%\end{array}$ & $47.37 \%$ & $36.84 \%$ & $21.05 \%$ & $15.79 \%$ & $36.84 \%$ \\
\hline $\begin{array}{l}\text { Aprobaron con 80\% 0 } \\
\text { más de logro }\end{array}$ & $21.05 \%$ & $52.63 \%$ & $42.11 \%$ & $42.11 \%$ & $42.11 \%$ \\
\hline
\end{tabular}

De estos resultados se puede establecer que:

- En cuanto a participación y logro en los foros virtuales, cerca de la tercera parte reprobó dichas actividades, siendo lo más usual que no participaron a lo largo de la semana, con lo que hicieron solo un aporte original hacia el final de ésta, sin que construyeran conocimiento a partir de los aportes de los compañeros o se limitaran a decir que estaban de acuerdo o en desacuerdo.

- Hay un cambio positivo entre los primeros dos foros y los segundos, en el sentido de que el nivel de logro del $67 \%$ de participantes subió significativamente entre el primero y el segundo grupo de foros.

- En lo que respecta al trabajo de diseño, es mayor el nivel de logro a nivel macro (de curso, cerca del 90\%) que de unidad (cerca del 60\%), a pesar de que hubo flexibilidad en los tiempos de entrega de productos y que la retroalimentación entre pares, haciendo uso de la rúbrica 2, fue considerada muy útil. La razón principal que se arguyó fue de índole conceptual y práctico. Para algunos fue muy difícil romper esquemas mentales de diseño educativo centrado en contenidos y para otros, que tenían a cargo labores más administrativas que docentes, fue difícil aterrizar las ideas en temas relevantes y de su dominio.

- Cuantitativamente hablando, los niveles globales de logro académico en el segundo nivel del Seminario de Didáctica 2, no difieren significativamente de los del nivel 1, en ambos el nivel de aprobación es de alrededor del $80 \%$. Esto pudiera hacer pensar que el mayor esfuerzo procesando información previa a las sesiones presenciales y la asesoría individual durante éstas a los trabajos de cada persona, no arroja diferencia significativa en cuanto a proporciones de nivel de

Aprendiendo de una transformación de prácticas pedagógicas en cursos de maestría en la modalidad híbrida de aprendizaje. Álvaro Hernán Galvis, Yelenis Yanit López González y Marlín Alicia Aarón Gonzálvez. 
logro global. Siendo la nota final una variable compuesta, el peso de las distintas actividades hace la diferencia, así como los condicionantes de cada quien para tomar parte en el proceso.

Para resolver la inquietud de si las percepciones en niveles 1 y 2 eran semejantes o si y en qué diferían, también se recabó información de retorno de los participantes al finalizar el seminario, y se detectaron cambios significativos en las percepciones y en los comentarios y recomendaciones, pues pasaron del 100\% de satisfacción en nivel 1 a cerca del $67 \%$ en nivel 2. Doce de 19 estudiantes respondieron la encuesta de fin de curso (64\% de los inscritos); tomando esta cifra como referente, cerca de las $2 / 3$ partes de los respondientes consideró que las dos sesiones presenciales fueron excelentes o buenas, mientras que los demás las consideraron regulares.

Quienes participaron en las actividades virtuales y presenciales dicen que fue excelente la forma como se adelantó el seminario, pues "recrea la forma en la que podemos hacer pedagogía activa al interior del aula y propicia aprendizajes profundos y significativos"; también consideraron "excelente la manera como se inserta en el proceso la compañía de la docente asistente, Yelenis, quien enriquece el proceso".

La mayor crítica de parte del tercio que no está del todo satisfecho está ligada al ritmo de las actividades virtuales, un foro por semana, el cual fue difícil de marcar cuando hubo limitado acceso a recursos digitales para las actividades, toda vez que cuesta marcarlo cuando en el lugar de residencia o de trabajo no hay acceso pleno a tecnología, como le pasa a quienes no viven en zona urbana, en particular por fluctuaciones de fluido eléctrico. Por otra parte, dado que en este segundo seminario de didáctica no hubo ajustes a la previsión de actividades presenciales como en el primero, quienes no participaron en las actividades virtuales preparatorias se sintieron en desventaja al tratar de aplicar los conceptos sin tenerlos claros, a pesar de que cabía revisar los materiales y pedir ayuda al respecto; hubo malestar porque no hubo explicaciones generales frente a dudas particulares, sino orientación personal acerca de dónde remediar las carencias. También hubo comentarios respecto a la necesidad de valorar los ejercicios en clase por parte del docente, toda vez que la retroalimentación entre pares no funciona bien cuando hay disparidad entre las duplas.

\section{Análisis de resultados a profundidad}

Más allá del análisis de resultados académicos y de percepciones de los estudiantes al finalizar el seminario de nivel 2, la investigación-acción educativa propuesta llevó a consultar a los distintos actores de la tercera cohorte de la MPTIC acerca de lecciones aprendidas con la transformación pedagógica hecha en el segundo nivel del Seminario de Didáctica, y triangular las respectivas respuestas. Esto incluyó: 19 estudiantes de tercer semestre de la MPTIC (todos ellos docentes en servicio), 2 docentes-facilitadores (titular y auxiliar) de los seminarios de Didáctica Aplicada I y II de la maestría, así como a los 2 directivos que acompañan el proceso.

A cada uno de estos actores consultados se les indagó, desde su rol y perspectiva, respecto a:

Aprendiendo de una transformación de prácticas pedagógicas en cursos de maestría en la modalidad híbrida de aprendizaje. Álvaro Hernán Galvis, Yelenis Yanit López González y Marlín Alicia Aarón Gonzálvez. 
1. ¿Por qué valió la pena, o no, que los estudiantes participaran en discusiones conceptuales en la red, previas a las sesiones presenciales de aplicación de los conceptos a su proyecto de profundización en la MPTIC?

2. ¿Cuáles fueron los retos y logros principales en la construcción y aplicación de conocimiento en los niveles 1 y 2 de estos seminarios?

3. ¿Qué recomiendan a la MPTIC en lo relacionado con propiciar aprendizaje conceptual mediante foros virtuales, previo a las sesiones de aplicación en contexto?

Para la solución de la primera pregunta con los estudiantes, se abrió un espacio de reflexión al inicio de la reunión presencial que siguió a las dos semanas de interacción en la red en las que se llevaron a cabo los dos primeros foros virtuales, de modo que cada uno escribió sus respuestas, las compartió con un pequeño grupo de compañeros y las socializó con el plenario en un conversatorio facilitado por el docente titular del seminario. La relatoría de esta sesión y los hallazgos de este diálogo fueron sintetizados por la docente auxiliar.

Para la solución de las otras dos preguntas a partir de los estudiantes, la docente auxiliar condujo entrevistas semi-estructuradas con ellos durante la quincena que siguió a la primera sesión presencial, tratando de profundizar en sus percepciones acerca del uso de la metodología de aula invertida en modalidad híbrida, haciendo uso de foros virtuales para llegar al conocimiento y de talleres presenciales para su aplicación en contexto relevante.

Los interrogantes de base para estas entrevistas fueron:

¿Cómo se sintió con esta metodología? ¿Qué dificultades tuvo en su aplicación? ¿qué lecciones le deja como estudiante de la MPTIC? ¿Qué utilidad tiene la vivencia para su proyecto de profundización y para otros seminarios de la maestría?

Al finalizar el segundo seminario de didáctica, a los docentes facilitadores del proceso se les pidió dar respuesta escrita a los tres interrogantes, cada uno desde su rol.

A los directivos de la MPTIC que acompañaron los seminarios se les pidió dar respuesta escrita a los interrogantes, desde su lente de acompañantes del proceso.

A partir de los aportes de cada grupo de actores se hizo triangulación de datos, como base para sacar conclusiones y formular recomendaciones.

\subsection{Hallazgos acerca la transformación pedagógica realizada}

En este aparte se busca develar los sentires, emociones y aprendizajes de los distintos actores de la MPTIC, contrastando con las pretensiones de los directivos del programa y con las intenciones pedagógicas de los docentes involucrados en el proceso. Parafraseando a Ghiso (1999), en este ejercicio metodológico se debe comunicar la novedad, desde el lente de los actores principales del aula, bajo el entendido de que la recuperación de la experiencia vivida en ella permite reflexionar, actuar y transformar

Aprendiendo de una transformación de prácticas pedagógicas en cursos de maestría en la modalidad híbrida de aprendizaje. Álvaro Hernán Galvis, Yelenis Yanit López González y Marlín Alicia Aarón Gonzálvez. 
las prácticas, encontrando los caminos que conduzcan a la verdadera educación con sentido y significación.

Ahora bien, encontrar los caminos, o hacerlos, implica escuchar las voces de los participantes para ir ajustándose a las necesidades sentidas conceptuales y contextuales que van mostrando las pistas para abordar el para qué y qué, así como, la buena forma para propiciar un aprendizaje comprensivo y el rediseño de estrategias, didácticas y recursos aplicables.

\subsubsection{Opiniones de los estudiantes de la maestría}

Recogiendo las expresiones de los estudiantes se revelan sus opiniones sobre sus impresiones ante la transformación pedagógica llevada a cabo en los seminarios, con base en las preguntas que orientaron las entrevistas se exponen los resultados en la tabla 3.

Los maestrantes reconocen y valoran positivamente el cambio metodológico, a pesar de que, al principio, mostraban resistencia al nuevo sistema, por la cantidad de tiempo demandado en el proceso y por el desconocimiento de la novedad; sin embargo, consideran muy valioso el proceso para llegar a un aprendizaje profundo y desarrollar la capacidad de aprender a aprender autónomamente.

Muy interesante observar que en su retroalimentación hacen uso de algunos de los conceptos objeto de estudio en estos seminarios.

Aprendiendo de una transformación de prácticas pedagógicas en cursos de maestría en la modalidad híbrida de aprendizaje. Álvaro Hernán Galvis, Yelenis Yanit López González y Marlín Alicia Aarón Gonzálvez. 
RED. Revista de Educación a Distancia, Núm. 58. Artíc. 2

31-10-2018

DOI: http://dx.doi.org/10.6018/red/58/2

http://www.um.es/ead/red/58/galvis_et_al.pdf

Tabla 3. Percepciones de los estudiantes acerca del uso de la metodología de aula invertida en modalidad híbrida

\begin{tabular}{|c|c|c|c|c|}
\hline $\begin{array}{c}\text { Actores del proceso de } \\
\text { transformación } \\
\text { Pedagógica }\end{array}$ & \multicolumn{3}{|c|}{$\begin{array}{l}\text { Categorías } \\
\text { /Preguntas }\end{array}$} & $\begin{array}{l}\text { Impacto de los } \\
\text { aprendizajes }\end{array}$ \\
\hline Estudiantes & 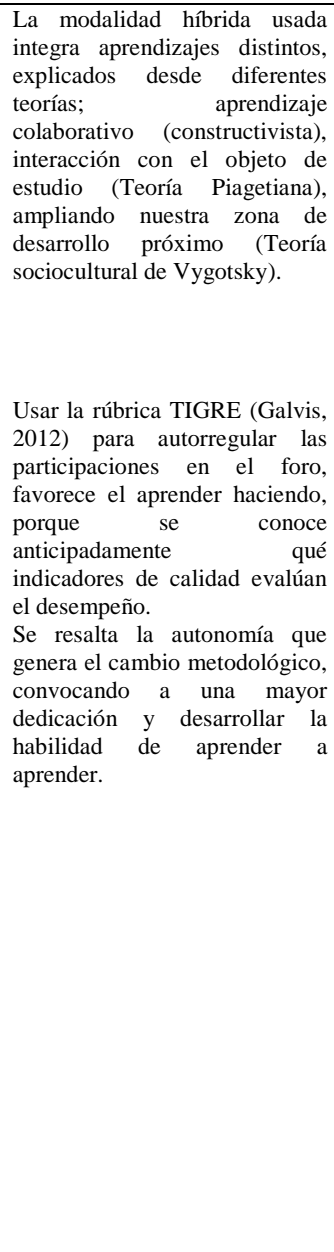 & 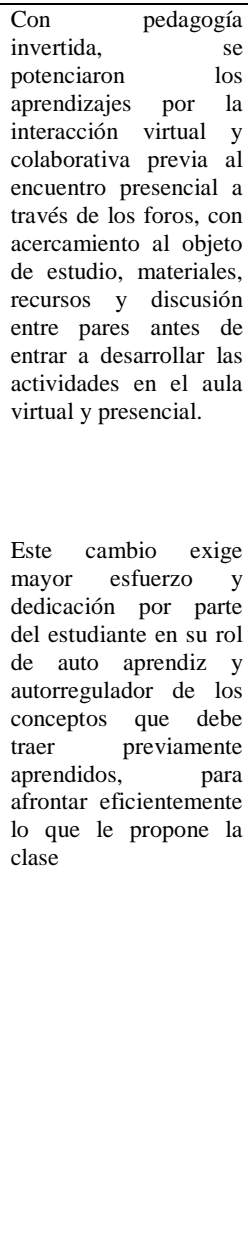 & 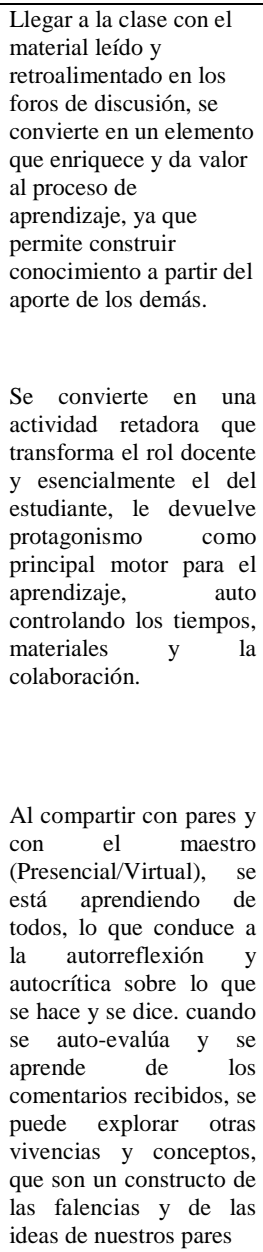 & $\begin{array}{l}\text { Valorar el proceso a } \\
\text { través de consultar con } \\
\text { el compañero de al } \\
\text { lado y llegar a } \\
\text { acuerdos sobre el } \\
\text { conocimiento } \\
\text { aprendido, Coevaluar y } \\
\text { autoevaluarse, exige } \\
\text { elevar los niveles de } \\
\text { pensamiento. } \\
\text { Este cambio configura } \\
\text { una innovación } \\
\text { educativa en el aula, da } \\
\text { las pautas para replicar } \\
\text { en otros contextos. }\end{array}$ \\
\hline
\end{tabular}

Tabla 3 continúa en página siguiente

Aprendiendo de una transformación de prácticas pedagógicas en cursos de maestría en la modalidad híbrida de aprendizaje. Álvaro Hernán Galvis, Yelenis Yanit López González y Marlín Alicia Aarón Gonzálvez. 
RED. Revista de Educación a Distancia, Núm. 58. Artíc. 2

31-10-2018

DOI: http://dx.doi.org/10.6018/red/58/2 http://www.um.es/ead/red/58/galvis_et_al.pdf

\begin{tabular}{|c|c|c|c|c|}
\hline \multirow{2}{*}{$\begin{array}{l}\text { Actores del proceso de } \\
\text { transformación } \\
\text { Pedagógica }\end{array}$} & \multicolumn{3}{|c|}{$\begin{array}{l}\text { Categorías / } \\
\text { Preguntas }\end{array}$} & \multirow[b]{2}{*}{$\begin{array}{l}\text { Impacto de los } \\
\text { aprendizajes }\end{array}$} \\
\hline & $\begin{array}{c}\text { Opiniones / } \\
\text { Expectativas }\end{array}$ & $\begin{array}{c}\text { Ventajas / } \\
\text { limitaciones }\end{array}$ & $\begin{array}{l}\text { Experiencia / } \\
\text { Impresiones }\end{array}$ & \\
\hline Estudiantes & $\begin{array}{l}\text { Pasar de un modelo } \\
\text { tradicional a este modelo } \\
\text { activo que está a la } \\
\text { vanguardia y pretende ser } \\
\text { el eje de todo el sistema } \\
\text { educativo, requiere mayor } \\
\text { esfuerzo y participación. } \\
\\
\text { El aprendizaje ha sido } \\
\text { bastante grande, se } \\
\text { necesita mucha más } \\
\text { preparación para poder } \\
\text { llevarlo a la práctica } \\
\text { docente; no es una tarea } \\
\text { fácil, es poco a poco cómo } \\
\text { se logra el cambio. Se } \\
\text { debe tomar conciencia y } \\
\text { convencimiento, para } \\
\text { luego llevarlo a la praxis. }\end{array}$ & $\begin{array}{l}\text { Produce un } \\
\text { desequilibrio por los } \\
\text { elementos nuevos que } \\
\text { trae y esto exige } \\
\text { adaptación; salir de la } \\
\text { zona de confort y } \\
\text { equilibrarse o dejar } \\
\text { pasar esta gran } \\
\text { oportunidad de } \\
\text { construir } \\
\text { conocimientos juntos. } \\
\text { Esta innovación en el } \\
\text { aula es un reto } \\
\text { pedagógico, que } \\
\text { cuesta mucho } \\
\text { adaptarse cuando se } \\
\text { viene de un esquema } \\
\text { de pensamiento } \\
\text { tradicional y aunque } \\
\text { se ha avanzado en } \\
\text { conocimiento, se } \\
\text { siente que falta mucho } \\
\text { por alcanzar, pero es } \\
\text { muy positivo el } \\
\text { resultado. }\end{array}$ & $\begin{array}{l}\text { Con esta propuesta } \\
\text { estamos volviendo a } \\
\text { los enfoques y teorías } \\
\text { de aprendizajes ya } \\
\text { vistos, aplicando la } \\
\text { evaluación auténtica y } \\
\text { coevaluación a través } \\
\text { de la Rúbrica Tigre } \\
\text { (Galvis, 2012), la cual } \\
\text { es bastante compleja } \\
\text { pero interesante, hay } \\
\text { que ponerla en práctica } \\
\text { y vamos por buen } \\
\text { camino. }\end{array}$ & $\begin{array}{l}\text { Este modelo ha marcado } \\
\text { la práctica } \\
\text { con mucha confusión en } \\
\text { el arranque para llegar al } \\
\text { entendimiento de la } \\
\text { estructura y la estrategia, } \\
\text { pero en la medida en que } \\
\text { se apropian los } \\
\text { conceptos, este inspira y } \\
\text { motiva a aplicarlos en los } \\
\text { entornos educativos, } \\
\text { generando un mayor } \\
\text { conocimiento para los } \\
\text { procesos de EA en el } \\
\text { aula. }\end{array}$ \\
\hline
\end{tabular}

\subsubsection{Opiniones de los directivos de la MPTIC}

Desde la visión y pretensiones de los directivos de la MPTIC, se describen los resultados observados y las preocupaciones generadas en torno al cambio de la pedagogía activa convencional a la pedagogía activa invertida; un modo distinto de abordar el aprendizaje frente a un modo distinto de llegar al conocimiento.

Aprendiendo de una transformación de prácticas pedagógicas en cursos de maestría en la modalidad híbrida de aprendizaje. Álvaro Hernán Galvis, Yelenis Yanit López González y Marlín Alicia Aarón Gonzálvez. 
RED. Revista de Educación a Distancia, Núm. 58. Artíc. 2

DOI: http://dx.doi.org/10.6018/red/58/2 http://www.um.es/ead/red/58/galvis_et_al.pdf

Tabla 4. Percepciones de los Coordinadores de MPTIC acerca del uso de la metodología de aula invertida en modalidad hibrida

\begin{tabular}{|c|c|c|c|c|}
\hline \multirow{2}{*}{$\begin{array}{l}\text { Actores del proceso de } \\
\text { transformación } \\
\text { Pedagógica }\end{array}$} & \multicolumn{3}{|c|}{$\begin{array}{l}\text { Categorías / } \\
\text { Preguntas }\end{array}$} & \multirow[b]{2}{*}{$\begin{array}{l}\text { Impacto de los } \\
\text { aprendizajes }\end{array}$} \\
\hline & $\begin{array}{c}\text { Opiniones / } \\
\text { Expectativas }\end{array}$ & $\begin{array}{c}\text { Ventajas / } \\
\text { Limitaciones }\end{array}$ & $\begin{array}{l}\text { Experiencia / } \\
\text { Impresiones }\end{array}$ & \\
\hline $\begin{array}{c}\text { Coordinadores de la } \\
\text { MPTIC }\end{array}$ & $\begin{array}{lr}\text { Con este cambio de } \\
\text { metodología } & \text { los } \\
\text { estudiantes de } & \text { la } \\
\text { maestría están llegando } \\
\text { mejor preparados al } \\
\text { aula. }\end{array}$ & $\begin{array}{l}\text { La propuesta } \\
\text { metodológica les } \\
\text { aporta a los } \\
\text { estudiantes un } \\
\text { escenario inicial de } \\
\text { identificación, } \\
\text { expresada tanto en } \\
\text { tiempos como en cada } \\
\text { una de las actividades } \\
\text { que deben desarrollar } \\
\text { con sus respectivos } \\
\text { resultados. }\end{array}$ & $\begin{array}{l}\text { Para muchos el } \\
\text { trabajo virtual } \\
\text { previo al encuentro } \\
\text { presencial lo } \\
\text { perciben como una } \\
\text { carga, sin embargo, } \\
\text { la valoración que } \\
\text { hacen sobre el } \\
\text { proceso es positiva, } \\
\text { porque sienten que } \\
\text { obtienen un } \\
\text { aprendizaje } \\
\text { profundo. }\end{array}$ & $\begin{array}{l}\text { La preparación } \\
\text { previa } \\
\text { seminario } \\
\text { presencial } \\
\text { permite al } \\
\text { estudiante pensar } \\
\text { críticamente y } \\
\text { reflexionar sobre } \\
\text { lo que debe hacer } \\
\text { y contrastar estas } \\
\text { acciones con su } \\
\text { quehacer en el } \\
\text { aula de clases; } \\
\text { esta criticidad le } \\
\text { genera una } \\
\text { apropiación y un } \\
\text { aprendizaje } \\
\text { distintos. }\end{array}$ \\
\hline $\begin{array}{c}\text { Coordinadores de la } \\
\text { MPTIC }\end{array}$ & $\begin{array}{l}\text { Existen tensiones } \\
\text { relacionadas con la } \\
\text { estructura de } \\
\text { pensamiento porque la } \\
\text { mayoría vienen de una } \\
\text { modalidad de } \\
\text { pensamiento tradicional } \\
\text { en su hacer en el aula; } \\
\text { sin embargo, se } \\
\text { visibilizan los avances, } \\
\text { porque están } \\
\text { apropiándose de la } \\
\text { innovación e intentando } \\
\text { aplicarla con sus } \\
\text { particulares choques y } \\
\text { dificultades. }\end{array}$ & $\begin{array}{l}\text { Muchos estudiantes } \\
\text { tienen una gran } \\
\text { claridad sobre la } \\
\text { apropiación de } \\
\text { conceptos y su } \\
\text { aplicación y es } \\
\text { notoria la } \\
\text { concientización que } \\
\text { tienen frente al } \\
\text { proceso. Otros deben } \\
\text { hacer un tránsito más } \\
\text { largo, por la } \\
\text { resistencia que } \\
\text { muestran frente al } \\
\text { cambio. }\end{array}$ & $\begin{array}{l}\text { Algunos estudiantes, } \\
\text { tienen debilidad en } \\
\text { la manera de llegar } \\
\text { al conocimiento, } \\
\text { poca dedicación al } \\
\text { estudio y reflexión, } \\
\text { no siguen las } \\
\text { instrucciones y } \\
\text { orientaciones } \\
\text { propuestas, o } \\
\text { simplemente tienen } \\
\text { conceptos errados y } \\
\text { previos deficientes. } \\
\text { Se deben crear } \\
\text { espacios y } \\
\text { estrategias de } \\
\text { acompañamiento } \\
\text { entre pares, con el } \\
\text { estudiante que pueda } \\
\text { fortalecer al otro con } \\
\text { debilidades. }\end{array}$ & $\begin{array}{l}\text { El cuestionar y } \\
\text { criticar sobre el } \\
\text { conocimiento } \\
\text { apropiado, genera } \\
\text { sensibilidad y } \\
\text { responsabilidad } \\
\text { hacia el proceso } \\
\text { de aprender y } \\
\text { sobre todo, hacia } \\
\text { trasladarlo a la } \\
\text { práctica, en la } \\
\text { búsqueda de una } \\
\text { transformación } \\
\text { de su quehacer } \\
\text { docente y sus } \\
\text { entornos } \\
\text { educativos. }\end{array}$ \\
\hline
\end{tabular}

Opinan los directivos de la maestría que las pretensiones de ésta, con el desarrollo de sus seminarios, son que el estudiante-docente de la MPTIC se preocupe y se ocupe porque su práctica sea transformada e impacte su contexto educativo. Con este objetivo misional, la maestría espera que el estudiante sea un agente de cambio cultural en su comunidad, que haya una permanente continuidad innovadora de su trabajo, generando transformaciones profundas que permitan identificar las estrategias y metodologías propiciadoras del cambio radical de sus prácticas.

Aunque existan variables en algunos escenarios institucionales (modelo tradicional enraizado) que obstaculizan que el docente en formación o egresado irradie cambios en su contexto, los aprendices deben propiciar y lograr su propia emancipación a través de

Aprendiendo de una transformación de prácticas pedagógicas en cursos de maestría en la modalidad híbrida de aprendizaje. Álvaro Hernán Galvis, Yelenis Yanit López González y Marlín Alicia Aarón Gonzálvez. 
impactar su práctica, innovando la didáctica aplicada en el aula; esto permite que sea el propio estudiante (producto final del proceso), con sus vivencias, quien multiplique y difunda la novedad a partir de sus logros. Cuando esto ocurre, y se pudo evidenciar en el desarrollo de los seminarios a través de la metodología orientada, se genera mucha más completitud hacia el logro de objetivos de la Maestría en Pedagogía de las TIC.

Las dificultades que evidenciaron los estudiantes-docentes en relación con la comprensión de las actividades propias de la enseñanza a cargo de los docentesfacilitadores y la didáctica asociada, en la que debían involucrar en su propio entorno tareas y trabajos y definir para estos objetivos, precisar alcances, metas y logros, fue buena parte de las razones para cambiar modelos y métodos. Presentaban complicaciones para comprender lo que se les pedía; el vocabulario y el constructo teórico que manejaban el docente titular y la docente auxiliar, así como el dispuesto en las agendas de clases, no era bien comprendido por ellos y más aún, no estaba alineado con sus producciones; por ello, su resultado inicial en el desarrollo de actividades en contexto fue bajo; tuvieron que rehacer sus tareas. Y esto, también tiene que ver con las entradas previas de aprendizaje. Lo que traían aprendido y sabido como métodos o conceptos, no calzaba con lo que se les pedía.

Los estudiantes tuvieron que aprender a aprender estos nuevos procesos de enseñanza, siendo la pedagogía invertida lo que tuvo mayor dificultad, por cuanto ellos debían hacer comprensiones a partir de su propio trabajo, sin inducción previa a lo estudiado. Asociado esto al aprendizaje heurístico, por indagación y bajo su propio control, al que no estaban muy "acostumbrados", les dejó a algunos muchos sinsabores y rabias, porque ellos querían de manera inmediata ser tratados con pedagogía convencional y retroinformación conductista, es decir, que se les dijera enseguida, "esto está bien, o esto está mal".

Estas herencias de una vida de educación convencional generaban en los estudiantes muchos tropiezos, porque debían alinear sus presaberes con los contenidos dispuestos antes de clases (pedagogía invertida) y esto producía tensiones, llevándolos a tomar dos opciones; profundizar para reaprender, o no hacer nada y esperar la sesión de clases para buscar aprobación o desaprobación. La autogestión de la información, la construcción de conocimiento, y el aprender a aprender, se apalancó a partir de la estrategia de la pedagogía invertida que les generó la necesidad de contrastar e identificar para sí y para otros conceptos, términos y procesos que creían conocer, y además volverlos acción a través de tareas para desarrollo en su contexto.

La participación y observación directa de las sesiones presenciales y virtuales como miembros del equipo de la coordinación, le permitió a la MPTIC validar las calidades y condiciones de los docentes titular y auxiliar para poner en marcha metodologías y métodos previamente planeados y discutidos, a tono con las características y condiciones en las que estaban los estudiantes. El contexto (Gonzalvez Aaron, 2016) en este caso, las características de los estudiantes y sus resultados frente a las metodologías de enseñanza dispuestos en el primer nivel, generó en la MPTIC, en consonancia con los docentes titular y auxiliar, la necesidad de movilizar nuevas formas de propiciar el aprendizaje. Pasar de una estrategia de pedagogía activa tradicional a una estrategia de

Aprendiendo de una transformación de prácticas pedagógicas en cursos de maestría en la modalidad híbrida de aprendizaje. Álvaro Hernán Galvis, Yelenis Yanit López González y Marlín Alicia Aarón Gonzálvez. 
pedagogía activa invertida con la intención de generar transformación en el hacer pedagógico de los estudiantes, fue una decisión motivada significativamente por las características de los estudiantes como parte del contexto de enseñanza.

\subsubsection{Reflexión de los docentes a cargo de los seminarios}

En la tabla 5 se exponen las razones, opiniones y las valoraciones de los docentes titular y auxiliar, actores participantes del proceso de transformación pedagógica, de acuerdo con sus impresiones durante, antes y después de la implementación de la pedagogía invertida en modalidad blearning.

Aprendiendo de una transformación de prácticas pedagógicas en cursos de maestría en la modalidad híbrida de aprendizaje. Álvaro Hernán Galvis, Yelenis Yanit López González y Marlín Alicia Aarón Gonzálvez. 
RED. Revista de Educación a Distancia, Núm. 58. Artíc. 2

DOI: http://dx.doi.org/10.6018/red/58/2 http://www.um.es/ead/red/58/galvis_et_al.pdf

Tabla 5. Percepciones de los docentes acerca del uso de la metodología de aula invertida en modalidad hibrida

\begin{tabular}{|c|c|c|c|c|}
\hline \multirow{2}{*}{$\begin{array}{l}\text { Actores del proceso } \\
\text { de transformación } \\
\text { pedagógica }\end{array}$} & \multicolumn{4}{|c|}{$\begin{array}{c}\text { Categorías / } \\
\text { Preguntas }\end{array}$} \\
\hline & $\begin{array}{c}\text { Opiniones / } \\
\text { Expectativas }\end{array}$ & $\begin{array}{c}\text { Ventajas / } \\
\text { Limitaciones }\end{array}$ & $\begin{array}{l}\text { Experiencia / } \\
\text { Impresiones }\end{array}$ & $\begin{array}{l}\text { Impacto de los } \\
\text { aprendizajes }\end{array}$ \\
\hline $\begin{array}{l}\text { Docentes a cargo de } \\
\text { los seminarios }\end{array}$ & $\begin{array}{l}\text { La intención al } \\
\text { introducir cambios en } \\
\text { la metodología de } \\
\text { enseñanza fue } \\
\text { propiciar que los } \\
\text { estudiantes llegaran al } \\
\text { conocimiento de } \\
\text { forma autónoma y } \\
\text { conscientes de su } \\
\text { responsabilidad por } \\
\text { desarrollar su } \\
\text { capacidad de } \\
\text { aprender. }\end{array}$ & $\begin{array}{l}\text { Mediante la } \\
\text { participación, aportes y } \\
\text { colaboración en los } \\
\text { foros virtuales se buscó } \\
\text { involucrar al } \\
\text { activamente a los } \\
\text { estudiantes en el } \\
\text { proceso de apropiación } \\
\text { de conceptos, desde } \\
\text { antes de clase. Durante } \\
\text { el seminario } \\
\text { presencial, se buscó } \\
\text { reforzar la } \\
\text { participación } \\
\text { individual y grupal } \\
\text { mediante la interacción } \\
\text { (diálogo de saberes) y } \\
\text { desarrollo de las } \\
\text { actividades en el aula. } \\
\text { Después del seminario } \\
\text { presencial, se buscó } \\
\text { afianzar los conceptos } \\
\text { con la aplicación } \\
\text { práctica de los } \\
\text { conocimientos que } \\
\text { fueron obtenidos a } \\
\text { través de la } \\
\text { apropiación conceptual } \\
\text { temática y contextual }\end{array}$ & $\begin{array}{l}\text { En la modalidad } \\
\text { blended con } \\
\text { pedagogía activa } \\
\text { convencional usada } \\
\text { en } 2016 \text { se observó } \\
\text { que el estudiante } \\
\text { llegaba a la clase sin } \\
\text { haber leído, sin } \\
\text { preparación para } \\
\text { enfrentar las } \\
\text { exigencias de la } \\
\text { clase presencial. } \\
\text { Esto suele producir } \\
\text { desajuste en los } \\
\text { planes curriculares } \\
\text { y exige } \\
\text { reestructuración del } \\
\text { cronograma de } \\
\text { trabajo. } \\
\text { Al socializar el plan } \\
\text { de aprendizaje con } \\
\text { una inducción y } \\
\text { mediación inicial, } \\
\text { fue posible integrar } \\
\text { efectivamente la } \\
\text { pedagogía invertida } \\
\text { en el curso; al } \\
\text { avanzar en el } \\
\text { proceso, se descubre } \\
\text { que aumenta el } \\
\text { nivel de preparación } \\
\text { con base en la } \\
\text { participación en los } \\
\text { foros virtuales, lo } \\
\text { que hace una gran } \\
\text { diferencia, } \\
\text { demostrada en los } \\
\text { desempeños en el } \\
\text { aula presencial y } \\
\text { virtual. }\end{array}$ & 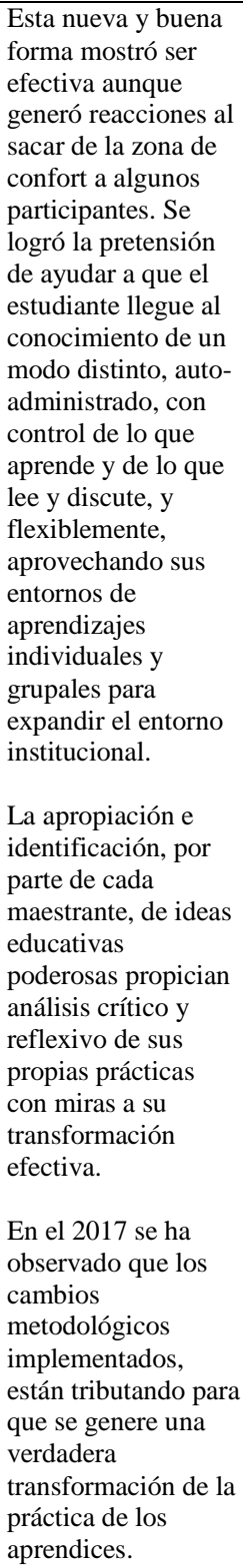 \\
\hline
\end{tabular}

\subsection{Análisis de los hallazgos}

Hay coherencia en las opiniones de los tres actores consultados respecto a que pasar de pedagogía activa convencional en modalidad Blended learning (donde se entremezclan espacios y tiempos para aprender) a pedagogía invertida en modalidad híbrida de aprendizaje (donde también se hizo mezcla de espacios y tiempos para aprender pero se cuidó que hubiese aprovechamiento efectivo de los entornos de aprendizaje autónomos), confronta tanto a docentes como a estudiantes a desarrollar un cambio significativo de

Aprendiendo de una transformación de prácticas pedagógicas en cursos de maestría en la modalidad híbrida de aprendizaje. Álvaro Hernán Galvis, Yelenis Yanit López González y Marlín Alicia Aarón Gonzálvez. 
sus roles. De parte de los docentes, exigió rediseño minucioso de los planes de enseñanza, cuidando que hubiera pedagogía activa a lo largo de todo el proceso, tanto en actividades virtuales como presenciales, uso relevante de los ETA-entornos tecnológicos de apoyo, trabajo individual y colaborativo, evaluación auténtica y facilitación desde el lado. Por parte de los estudiantes, exigió afinar y ejercitar su habilidad para aprender con autonomía y con recursos flexibles, lo que conlleva cambios en su estructura de pensamiento y en sus estrategias y medios de aprendizaje, mediante mayor esfuerzo cognitivo y mayor responsabilidad para trabajar en solitario y en colaboración, haciendo uso de recursos digitales.

La experiencia en el nivel 2 del Seminario de Didáctica Aplicada llevó a los estudiantesdocentes a transitar por maneras auto-gestionadas de aprender, por caminos que conducen en forma flexible al conocimiento, con la promesa de lograr aprendizajes comprensivos, profundos y duraderos. Coincidieron los aprendices entrevistados en que llegar preparados a cada sesión presencial, después de participación previa en ambiente virtual, les permite hacer uso de todo su potencial, pues vienen equipados con un bagaje conceptual, han hecho uso de colaboración entre pares y diálogo de saberes, pudiendo auto-evaluar y co-evaluar sus logros consultando los criterios de las rúbricas propuestas. Esta vivencia personal parece ser un paso firme en la transformación de su práctica como docentes en el contexto educativo donde se desempeñan, pues los talleres presenciales que siguen a la virtualidad exigen la reflexión y crítica de su quehacer en el aula, contrastada con lo aprendido en los seminarios.

Lo anterior confirma estudios previos de (López \& Martinez, 2016) quienes establecieron que el aprendizaje activo del proceso administrativo apoyado con TIC propicia el involucramiento del estudiante en las actividades propias de su saber, convirtiéndolos en agentes activos y participativos. Por otra parte, fue evidente en los trabajos aplicativos que el aprendizaje con pedagogía invertida convoca a cambios radicales en esquemas de pensamiento y de práctica docente, pasando de una estructura tradicional que se centra en logros a bajo nivel según la taxonomía de Bloom (Churches, 2008) a estructuras de pensamiento que se centran en niveles superiores. Se pudo constatar que estos modos de aprender propician autorreflexión crítica de la praxis, lo que puede incidir en la transformación del quehacer de los estudiantes como docentes y puede impactar a las comunidades educativas a cargo de cada quien.

Por otra parte, si bien los estudiantes-docentes consideran que la estrategia pedagógica usada en el nivel 2 es exigente, pues demanda tiempo y requiere producción basada en la reflexión y en la colaboración, identifican también el gran valor que ha tenido para ellos transitar en las actividades dispuestas. Se ven más competitivos como docentes, la comprensión de su vocabulario ha aumentado, mejorando la forma como se refieren a modelos, didácticas, evaluaciones, y demás aspectos analizados, así como sus competencias comunicativas.

Los resultados mostrados en el desarrollo de las diferentes actividades en los espacios virtual y presencial, evidencian las diferencias en el compromiso y la concientización de los estudiantes frente al reconocimiento del cambio metodológico; los que pusieron resistencia y consideraron una carga tener que llegar al conocimiento por sí mismos,

Aprendiendo de una transformación de prácticas pedagógicas en cursos de maestría en la modalidad híbrida de aprendizaje. Álvaro Hernán Galvis, Yelenis Yanit López González y Marlín Alicia Aarón Gonzálvez. 
coevaluar y recibir retroalimentación de sus compañeros, tomar parte colaborativamente en los foros virtuales previos al ambiente presencial, no arrojaron los mejores desempeños en las tareas propuestas en el currículo del seminario, lo cual contrasta con quienes compraron la idea y pusieron de su parte para superar la barrera de la enseñanza y entrar al terreno del aprendizaje auto-gestionado.

Lo vivido hizo evidente que la fase inicial de la pedagogía invertida -trabajo independiente en ETA propio- exige del aprendiz un mayor compromiso y responsabilidad en el proceso de aprender comprensivamente y en la forma de llegar al conocimiento, buscando con esto fortalecer sus habilidades para aprender a aprender conscientemente.

Fue evidente el impacto de la preparación previa en lo que se refiere a la interacción en el aula presencial, precedida por estudio y colaboración en ETA virtual. Las aportaciones de los estudiantes en las sesiones de clases presenciales con interacción socrática puesta en marcha por el docente titular fueron más centradas, pues se aplicaba y profundizaba con previo dominio conceptual, lo que permitió que en el trabajo práctico el análisis y las propuestas de acción en el entorno de cada estudiante fueran más focalizadas. Aunque hay mucho camino por recorrer, se observa la riqueza constructiva y deconstructiva que va logrando la pedagogía utilizada, se van dejando de lado algunas concepciones que en su rol de docente los estudiantes ponen en marcha, para dar paso a nuevas formas y maneras de actuar en el aula de clases.

Por último, fue notorio el rol desempeñado por la docente auxiliar, en sintonía y como complemento al docente titular. Su participación en los espacios virtuales haciendo facilitación desde el lado permitió hacer seguimiento uno a uno a cada estudiante y aportarles respuestas sobre inquietudes frente a su desempeño, así como acompañarlos para dar los pequeños (grandes) saltos frente a su propia práctica. La interacción entre el docente titular y el docente auxiliar se ha enriquecido, así como los resultados esperados, toda vez que el docente titular pudo dedicar buena parte de su tiempo a la orientación, alineación, y ajustes al seminario teniendo como referente la planificación hecha, construyendo sobre los hallazgos obtenidos a lo largo del proceso. Esta dupla de trabajo hizo posible atender los retos que se fueron presentando dentro de la flexibilidad que permiten los ambientes híbridos de aprendizaje.

\subsection{Reflexiones finales}

La expectativa es que esta golondrina sea precursora de verano en las prácticas de los maestrantes y de la comunidad educativa de la MPTIC. Al socializar esta experiencia esperamos que otros se animen a repensar sus prácticas y a aprender de la experiencia propia y ajena.

Institucionalmente esta innovación, que se hizo posible en la MPTIC por su espíritu abierto a la experimentación pedagógica, deja el reto de crear condiciones para hacer sostenible y expandir prácticas como las vividas en estos seminarios. El reconocimiento institucional al valor de la innovación educativa con TIC, al uso de modalidad híbrida de aprendizaje con pedagogía invertida, la valoración del esfuerzo diseñando y

Aprendiendo de una transformación de prácticas pedagógicas en cursos de maestría en la modalidad híbrida de aprendizaje. Álvaro Hernán Galvis, Yelenis Yanit López González y Marlín Alicia Aarón Gonzálvez. 
poniendo en práctica estas ideas, crean una ecología favorable para institucionalizar el cambio deseado.

\section{Conclusiones}

Desde el punto de vista del conocimiento que se generó (esencia de este documento) y de la experiencia adquirida de primera mano por los distintos actores del proceso, valió la pena la transformación de las prácticas pedagógicas al ajustar el modelo operativo del nivel 2, manteniendo el modelo educativo y la modalidad del nivel 1 del seminario de Didáctica Aplicada de la MPTIC, de la Universidad de la Guajira. Se hizo evidente que si bien con los ajustes hechos en el modelo operativo se crearon las condiciones para que hubiera participación más activa, individual y grupal, a lo largo de los momentos antes, durante y después de las sesiones presenciales, los efectos en lo que se refiere a logros académicos globales no difieren significativamente respecto a los del nivel 1, además de que las percepciones de los estudiantes respecto al esfuerzo y beneficio agregado disminuyen comparativamente, pero se diferencian cuando se toma en cuenta el nivel de participación en las distintas fases del proceso. Mientras que en el nivel 1 fue pleno el nivel de satisfacción con la metodología y modelos educativo y operativo usados, en el nivel 2 se pudo constatar que quienes participaron en las actividades a todo lo largo del proceso obtuvieron excelentes resultados y mostraron plena satisfacción, mientras que quienes no se sintieron cómodos con el nivel de exigencia del trabajo independiente y colaborativo para apropiar conceptos, también sintieron que la sesión presencial no les dio lo esperado - orientación sobre lo que había que estudiar-sino que reforzó la estrategia de llegar aprendido y de centrarse en aplicar el conocimiento en los talleres presenciales, con retroinformación entre pares y reflexión comprensiva a partir de las socializaciones por parte del docente titular. Las tensiones naturales entre distintas formas de llegar al conocimiento, aplicarlo y transferirlo a contexto propio, ayudan a entender las diferencias.

Desde el punto de vista de los docentes que tomaron parte en el cambio, la experiencia fue ocasión de reforzar la conveniencia de aplicar facilitación "desde el lado", tanto en entornos virtuales como presenciales. Mientras que en nivel 1 hubo que asumir en parte facilitación "desde el centro" al no venir los estudiantes preparados a las sesiones presenciales, en el nivel 2 se puso en práctica facilitación "desde el lado" tanto en el seminario virtual como en el taller presencial y en el seguimiento al mismo. Las rúbricas fueron muy importantes en este proceso, así como la consistencia en el acompañamiento para la aplicación de esta idea a lo largo de los tres momentos de la pedagogía invertida.

Institucionalmente, se hizo evidente la necesidad de desarrollar cultura sobre pedagogía activa, aula invertida y uso entornos híbridos de aprendizaje con apoyo de TIC, entre estudiantes y docentes de la MPTIC. Si bien conceptualmente hay plena alineación entre los conceptos orientadores del proceso y lo que se propone hacer en cada seminario, la implementación consistente de los mismos no es cuestión de un docente, sino del conjunto de ellos. En la medida en que esta experiencia sirve como objeto de reflexión, habrá valido la pena el esfuerzo de documentarla y aprender de ella.

Aprendiendo de una transformación de prácticas pedagógicas en cursos de maestría en la modalidad híbrida de aprendizaje. Álvaro Hernán Galvis, Yelenis Yanit López González y Marlín Alicia Aarón Gonzálvez. 
Riohacha y Bogotá, febrero de 2018

Presentación del artículo: 21 de marzo de 2018

Fecha de aprobación: 16 de junio de 2018

Fecha de publicación: 31 de Octubre de 2018

Galvis, Á.H, López, Y.Y, y Aarón, M.A. (2018). Aprendiendo de una transformación de prácticas pedagógicas en cursos de maestría en la modalidad híbrida de aprendizaje. RED. Revista de Educación a Distancia, 58 (2). Consultado el (dd/mm/aaaa) en http://www.um.es/ead/red/58/galvis_et_al.pdf

\section{Financiación}

Esta investigación no ha recibido ninguna subvención específica de los organismos de financiación en los sectores públicos, comerciales o sin fines de lucro.

\section{Agradecimientos}

Al Centro de Investigación de la Universidad de La Guajira.

El presente trabajo se inserta en el proyecto de investigación denominado" Construcción de un Escenario de Educación Avanzada a nivel de Maestría en la Universidad de La Guajira: Maestría en Pedagogía de las Tecnologías de la Información y la Comunicación“, del grupo MOTIVAR, el cual contó con auspicio del Centro de Investigación de la Universidad de La Guajira.

Aprendiendo de una transformación de prácticas pedagógicas en cursos de maestría en la modalidad híbrida de aprendizaje. Álvaro Hernán Galvis, Yelenis Yanit López González y Marlín Alicia Aarón Gonzálvez. 


\section{Apéndice 1. Glosario de términos}

Dejamos a consideración del lector la definición de los términos usados en este trabajo y las fuentes de las que se han tomado tales conceptos.

\section{Aprendizaje híbrido.}

Las actividades de aprendizaje híbrido no se limitan a lo que sucede en el aula (aulas presenciales y virtuales) sino que también incluyen actividades en espacios de aprendizaje autónomos; esto amplía el espacio y el tiempo para el aprendizaje y rompe el enfoque discreto al diseño de la instrucción. (Osorio Gómez, 2011, pág. 245). Modalidad educativa formal donde bajo la guía y supervisión del profesor el estudiante aprende de manera combinada: por una parte, a través de la entrega de contenidos e instrucción en línea y por otra parte a través de un formato presencial en el aula. El alumno bajo esta modalidad tiene la posibilidad de controlar algunos aspectos del proceso como el tiempo, lugar, ruta y ritmo, mantiene la posibilidad de interactuar con su profesor y sus compañeros (ITESM, 2017).

Aprendizaje invertido [en inglés, Flipped Classroom].

Técnica didáctica en la que la exposición de contenido se hace por medio de videos que pueden ser consultados en línea de manera libre, mientras el tiempo de aula se dedica a la discusión, resolución de problemas y actividades prácticas bajo la supervisión y asesoría del profesor (ITESM, 2017).

\section{Aula TIC.}

[En Uniguajira] Aula dispuesta para las sesiones de clase presenciales, que cuenta con la posibilidad de hacer uso de las TIC que el docente requiera: Audio, video, cámaras de grabación, sonido, videobeam, Internet, portátiles, impresora, escáner (UNIGUAJIRA MPTIC, 2011).

\section{Aula virtual.}

Entorno telemático en página web que permite la impartición de teleformación. Normalmente, en un aula virtual, el estudiantado tiene acceso al programa del curso, a la documentación de estudio y a las actividades diseñadas por el profesor. Además, puede utilizar herramientas de interacción como foros de discusión, charlas en directo y correo electrónico (ITSON EAD, sin fecha).

\section{Constructivismo social.}

Expresa que el aprendizaje escolar debe ser un proceso constructivo del conocimiento que el alumno elabora a través de actividades, aprendiendo a resolver situaciones problemáticas en colaboración con otros compañeros. Aprender a través de la actividad, descubrir y elaborar el conocimiento, resolver situaciones problemáticas y trabajar colaborativamente podría ser la síntesis básica de los principios del socioconstructivismo. (Vallejo \& Montes, 2010, pág. 238).

Aprendiendo de una transformación de prácticas pedagógicas en cursos de maestría en la modalidad híbrida de aprendizaje. Álvaro Hernán Galvis, Yelenis Yanit López González y Marlín Alicia Aarón Gonzálvez. 


\section{Diseño pedagógico.}

Creación de entornos de aprendizaje que se basa en la aplicación de una teoría de aprendizaje concreta. Esta debe estar bien definida (Martínez Ruiz \& Sauleda Parés, 2006).

eLearning [acrónimo de electronic Learning].

Herramienta al servicio de los profesionales de la formación, basada en teorías de aprendizaje humano, educación para adultos y aprendizaje acelerado, los cuales se combinan de forma creativa, con los últimos avances de la tecnología multimedia para activar los múltiples sentidos del usuario (Sáez Vacas F. , García, Palao, \& Rojo, sin fecha, pág. 7).

\section{Entendimiento.}

Tener claridad acerca de ideas, gente, situaciones y procesos que se manifiestan en varios comportamientos apropiados. Entender, es captar el sentido de lo que uno sabe, estar en capacidad de saber por qué es así, y tener la habilidad de usar dicho conocimiento en variedad de situaciones y contextos (Wiggins \& McTighe, 2005, pág. $353)$.

\section{Entendimiento perdurable.}

Se enuncia como una frase que ayude a enfocar a los estudiantes para tener una visión amplia y macro de los conceptos, buscando con ello hacer el aprendizaje significativo. Como dicen Wiggins y McTighe (2005), de lo que se trata es de diferenciar entre lo que tiene sentido saber, lo que es importante saber y hacer, y lo que es vital que le quede a uno para toda la vida. Esto último se suele llamar "entendimientos perdurables" y tienen que ver con los conceptos fundamentales o las "grandes ideas" de lo que se desea que el estudiante aprenda (Galvis \& Pedraza, 2012, pág. 23).

\section{Entorno.}

Conjunto de condiciones sociales, culturales, políticas, legales y económicas que influyen en la vida de un individuo u organización (Sáez Vacas F. , García, Palao, \& Rojo, s.f.).

\section{EPA-Entornos personales de aprendizaje.}

Son sistemas que los estudiantes pueden configurar ellos mismos para tomar el control y gestión de su propio aprendizaje: incluye el establecimiento de objetivos de aprendizaje, la gestión de los contenidos y comunicaciones con otros estudiantes. Estos entornos pueden estar compuestos de uno o varios subsistemas: LMS, blogs, feeds. Puede tratarse de una aplicación de escritorio o bien estar compuestos por uno o más servicios web (ITESM, 2017).

\section{Enfoque híbrido de aprendizaje.}

El concepto híbrido constituye un continuo potencial en el proceso de enseñanzaaprendizaje, ya que puede verse como la expansión y la continuidad del espacio-tiempo (cara a cara y distancia, sincrónico y asíncrono) en el entorno de aprendizaje. El desafío del enfoque híbrido es, por lo tanto, lograr la integración entre las acciones presenciales y de aprendizaje electrónico en la entrega de actividades de aprendizaje, de tal forma

Aprendiendo de una transformación de prácticas pedagógicas en cursos de maestría en la modalidad híbrida de aprendizaje. Álvaro Hernán Galvis, Yelenis Yanit López González y Marlín Alicia Aarón Gonzálvez. 
que cada una agregue valor a la otra en un proceso continuo que conduzca al logro de objetivos de aprendizaje (Osorio Gómez \& Duart, 2012, pág. 261).

\section{EVA-Entorno virtual de aprendizaje.}

Se trata de espacios digitales diseñados específicamente para desarrollar actividades educativas a distancia a través de Internet. En el entorno de aprendizaje los participantes disponen de recursos para facilitar la construcción de nuevos conocimientos y prácticas, con apoyo en las potencialidades de las tecnologías de la información y la comunicación. Incluyen materiales (textos electrónicos, kits de actividades o ejercicios, glosarios para consultas, claves para la autoevaluación, etc.) y flujos de comunicación y conocimiento (tutorías, correo electrónico, foros, chats, enlaces a bancos de información y páginas web, listas de interés, etc.) (OPS OMS, sin fecha).

\section{Evaluación auténtica.}

Evaluación de los aprendizajes compuesta de tareas de desempeño y actividades diseñadas para simular o replicar importantes desafíos del mundo real. El corazón de la evaluación auténtica son pruebas basadas en el desempeño realista: pedir al alumno que use el conocimiento en el mundo real, con propósitos genuinos, audiencias y variables situacionales (Wiggins \& McTighe, 2005, pág. 337). Incluye retos en contexto real, que se usan como estrategias de aprendizaje, y donde para guiar la indagación es esencial que haya preguntas que exijan altos niveles de pensamiento (Wiggins \& McTighe, 2001).

\section{Facilitación desde el lado.}

El facilitador efectivo se quita del medio de la discusión, y se vale de estrategias para estimular la colaboración real entre los estudiantes y para guiar la conversación hacia aquello que es importante en el contenido. El facilitador debe monitorear todas las discusiones y responder dentro de 24 horas las preguntas técnicas o que tienen que ver con procesos. Los líderes efectivos de comunidades en línea evitan interrumpir la colaboración de los participantes y promueven la construcción colaborativa de conocimiento interviniendo, cuando se necesita, para elevar el nivel de contenido de las discusiones o para que se profundice, así como para centrar el foco de la discusión (Collison, Elbaum, Haavind, \& Tinker, 2002).

\section{Foro virtual constructivista.}

Es un espacio de comunicación asincrónica organizado en cuadros de diálogo, en donde los alumnos pueden realizar aportaciones sobre un tema de discusión específico. Favorecen el desarrollo de actividades individuales, colectivas y colaborativas (Peralta Caballero \& Diaz-Barriga Arceo, 2010, pág. 5).

\section{Grandes ideas.}

Las grandes ideas son el material con el cual se logran entendimientos perdurables, importantes y transferibles. Son los conceptos fundamentales, principios, teorías y procesos que deben servir de punto focal al currículo, la instrucción y la evaluación (Wiggins \& McTighe, 2005, pág. 338).

\section{Guías de aprendizaje.}

Aprendiendo de una transformación de prácticas pedagógicas en cursos de maestría en la modalidad híbrida de aprendizaje. Álvaro Hernán Galvis, Yelenis Yanit López González y Marlín Alicia Aarón Gonzálvez. 
Las guías orientan a los participantes en el desarrollo de las actividades de aprendizaje. Constituyen una presentación y una "hoja de ruta", sobre la cual trabajar. Incluyen todas las indicaciones en términos de orientación y sugerencia: qué se espera lograr, cuáles serán los pasos, con qué materiales y herramientas, cuáles serán los intercambios y con qué condiciones, etc. (OPS OMS, sin fecha).

\section{Interrogante esencial.}

Pregunta que apunta al corazón de lo que se busca aprender y que promueve indagación y descubrimiento del asunto en estudio (Wiggins \& McTighe, 2005, pág. 342).

\section{IAP-Investigación Acción Participativa.}

Procedimiento reflexivo, sistemático, controlado y crítico que tiene por finalidad estudiar algún aspecto de la realidad, con una expresa finalidad práctica. La forma de realizar el estudio es ya un modo de intervención y que el propósito de la investigación está orientado a la acción, siendo ella a su vez fuente de conocimiento. En el proceso están involucrados tanto los investigadores (equipo técnico o agentes externos), como las mismas gentes destinatarias del programa, que ya no son consideradas como simples objetos de investigación, sino como sujetos activos que contribuyen a conocer y transformar la realidad en la que están implicados (Ander-Egg, 2003, pág. 4).

\section{Investigación Aplicada.}

Tiene por objetivo la generación de conocimiento con aplicación directa y a mediano plazo en la sociedad o en el sector productivo. Este tipo de estudios presenta un gran valor agregado por la utilización del conocimiento que proviene de la investigación básica. De esta manera, se genera riqueza por la diversificación y progreso del sector productivo. La investigación aplicada impacta indirectamente en el aumento del nivel de vida de la población y en la creación de plazas de trabajo (Lozada, 2014, pág. 35).

\section{LMS_Learning Management System.}

Programa informático usado para administrar, documentar y seguir el progreso de las actividades de una clase. Con su uso, los profesores y el personal de un centro educativo pueden aumentar su efectividad (Santos, 2013).

\section{Metodología de Seminario.}

Técnica de enseñanza concebida desde el desarrollo de actividades formativas teóricoprácticas dirigidas a la profundización de los temas que hacen parte de la estructura curricular que se cursa, referida a áreas fundamentales de estas, que asocia presaberes, saberes y habilidades para el abordaje de problemas de su entorno y contexto, así como de otros en los que intervenga el estudiante (UNIGUAJIRA - MPTIC, 2011).

Modalidad combinada de aprendizaje [en inglés, blended learning, abreviada como bLearning].

Formato para ofrecer educación bajo la guía y supervisión del profesor donde el estudiante aprende de manera combinada: por una parte, a través de la entrega de contenidos e instrucción en línea y por otra parte a través de un formato presencial en el aula. El alumno bajo esta modalidad tiene la posibilidad de controlar algunos aspectos

Aprendiendo de una transformación de prácticas pedagógicas en cursos de maestría en la modalidad híbrida de aprendizaje. Álvaro Hernán Galvis, Yelenis Yanit López González y Marlín Alicia Aarón Gonzálvez. 
del proceso como el tiempo, lugar, ruta y ritmo, mantiene la posibilidad de interactuar con su profesor y sus compañeros. (ITESM, 2017).

\section{Modelo educativo.}

Visiones sintéticas o enfoques pedagógicos que orientan a los profesores en la elaboración de programas de estudios, en la sistematización del proceso de enseñanzaaprendizaje o como una base para el análisis y la comprensión de un programa de estudios (Flores \& García, 2011, pág. 30).

\section{Modelo operativo.}

Definición detallada de las líneas de acción a ejecutar, los medios requeridos y los agentes ejecutores para lograr el futuro propuesto para el objeto o sistema a planificar (Graffe, 2006, pág. 7).

\section{Pedagogía activa.}

Forma de enseñar que permite establecer una organización docente dirigida a eliminar la pasividad del alumno, la memorización de conocimientos transmitidos, utilizando una didáctica de respuesta, necesidades internas que enseña entre otras cosas a vencer de manera consciente las dificultades (Pérez Serrano, 2006).

\section{Pensamiento crítico.}

Habilidad de examinar y analizar la información e ideas con el fin de entender y evaluar sus valores y supuestos, en lugar de simplemente aceptar las propuestas por su valor nominal (UNESCO, 2011, pág. 194).

\section{Proyecto de profundización.}

[En Uniguajira] Es un trabajo de grado que realizan los estudiantes centrado en su propia práctica sobre la que deben generar una innovación pedagógica, después de analizar cuáles son las necesidades educativas de mayor relevancia que consideran deben solucionar. El proyecto es un artefacto pedagógico apoyado por las TIC, que se pone en marcha. No es un documento para escribir. Es una acción pedagógica que debe transformar el aula y transformarlos (UNIGUAJIRA - MOTIVAR, 2010).

\section{Rúbrica (Matriz de evaluación).}

Guía para calificar que está basada en criterios, permite a los evaluadores tomar decisiones confiables y les permite a los aprendices auto-evaluarse en una o más dimensiones del comportamiento esperado (Wiggins \& McTighe, 2005, pág. 349).

\section{Tecnología digital.}

Materiales o herramientas a los cuales el ser humano les incorpora, mediante un lenguaje matemático, instrucciones que se traducen en acciones para resolver un problema o desafío (González García, 2005, pág. 8).

Aprendiendo de una transformación de prácticas pedagógicas en cursos de maestría en la modalidad híbrida de aprendizaje. Álvaro Hernán Galvis, Yelenis Yanit López González y Marlín Alicia Aarón Gonzálvez. 


\section{TIC-Tecnologías de Información y Comunicación.}

Son todos los medios técnicos que se utilizan para manejar la información y facilitar la comunicación, incluyendo hardware de computadoras y redes, así como también todo el software necesario (UNESCO, 2011).

\section{TIGRE - Rúbrica.}

TIGRE es un acrónimo que sirve como referente para la rúbrica con la que se autocontrola la calidad de los aportes en discusiones pragmáticas. $\mathbf{T}$ hace referencia a un Título diciente, que refleje el contenido del mensaje. I denota la Ilación que es deseable entre aportes. $\mathbf{G}$ hace referencia a que los aportes deben Generar más discusión. $\mathbf{R}$ trae a colación la importancia de la buena Redacción y presentación. La $\mathbf{E}$ pone de presente la necesidad de Enriquecer la discusión, de agregar valor a la misma (Galvis, 2007).

\section{Tutoría.}

Modalidad de desarrollo de la tarea docente, basada en el apoyo y acompañamiento del proceso de aprendizaje individual y grupal. A diferencia de la posición docente de "enseñante", la tutoría destaca el papel de facilitador, estimulador, dinamizador de la participación y la elaboración activa del aprendizaje de los participantes. Modera las participaciones y debates, facilita el acceso a las fuentes y acompaña el desarrollo de las actividades programadas, provocando la reflexión, valorando los progresos y desafiando a mayores logros. El tutor busca el perfeccionamiento posible de las producciones de los participantes, dentro del encuadre del curso o programa (OPS OMS, sin fecha).

\section{Transformación Pedagógica.}

Aquellos estilos de enseñanza aprendizaje que generan innovaciones educativas que cambian las formas tradicionales de aprender centradas en la transmisión de información, por modelos pedagógicos que promueven el análisis, la comprensión, la interacción y la construcción social del conocimiento (Garcés-Prettel, Ruiz-Cantillo, \& Martínez Ávila, 2014, pág. 218).

Aprendiendo de una transformación de prácticas pedagógicas en cursos de maestría en la modalidad híbrida de aprendizaje. Álvaro Hernán Galvis, Yelenis Yanit López González y Marlín Alicia Aarón Gonzálvez. 


\section{Apéndice 2. Diseño educativo del Seminario de Didáctica Aplicada - Nivel 1}

\begin{tabular}{|c|c|}
\hline $\begin{array}{l}\text { Gran idea } 1 \text { (GI1) / } \\
\text { Concepto fundamental } \\
\text { que debe perdurar en el } \\
\text { tiempo }\end{array}$ & $\begin{array}{l}\text { GI1. El aprendizaje se da tanto mediante procesos de enseñanza } \\
\text { como en procesos de exploración, reflexión y colaboración, en } \\
\text { multitud de ambientes y con variedad de recursos educativos. }\end{array}$ \\
\hline $\begin{array}{l}\text { Resultado observable } 1 \\
\text { (RO1) / lo que el } \\
\text { estudiante entrega para } \\
\text { evaluar }\end{array}$ & $\begin{array}{l}\text { RO1. Al finalizar este seminario cada quien ilustrará con } \\
\text { ejemplos propios los enfoques educativos algorítmico y } \\
\text { heurístico, así como los conceptos de aprendizaje bajo } \\
\text { aproximaciones conectivista, constructivista, cognitivista y } \\
\text { conductista. Se aceptará si escribe un ensayo corto (a lo sumo tres } \\
\text { páginas) y resuelve un examen, con apuntes, donde demuestre uso } \\
\text { coherente de los conceptos claves en cada una de las } \\
\text { aproximaciones al aprendizaje y enfoques educativos estudiados. }\end{array}$ \\
\hline $\begin{array}{l}\text { Sistema evaluación de } \\
\text { los aprendizajes }\end{array}$ & $\begin{array}{l}\text { Se hará uso de rúbrica } 1 \text { para auto-evaluar, co-evaluar y hetero- } \\
\text { evaluar el ensayo del RO1. } 60 \% \text { nota final, con base en hetero- } \\
\text { evaluación. } \\
\text { Habrá examen con apuntes abiertos, para resolver pequeños casos } \\
\text { que demuestren uso de conceptos del RO1. } 40 \% \text { nota final. }\end{array}$ \\
\hline $\begin{array}{l}\text { Interrogantes } \\
\text { esenciales (IE1.x, } \mathrm{x}=1 \text {, } \\
2,3 \text { ) / andamios para } \\
\text { llegar al conocimiento }\end{array}$ & $\begin{array}{l}\text { IE1.1 ¿De qué manera(s) aprendo yo? ¿Qué me motiva a } \\
\text { aprender? ¿En qué entornos de aprendizaje? ¿Haciendo uso de } \\
\text { qué estrategias metodológicas? ¿Valiéndome de qué medios o } \\
\text { recursos? ¿Cómo sé que he aprendido lo deseado o requerido?. } \\
\text { Habrá co-evaluación y socialización en plenaria. } \\
\text { IE1.2 ¿Qué tan conductistas, constructivistas, cognitivistas y/o } \\
\text { conectivistas son los entornos de aprendizaje con los que llego al } \\
\text { conocimiento, lo afianzo y generalizo? ¿Con qué enfoque } \\
\text { educativo me siento más cómodo? ¿Por qué? Dar ejemplos. Co- } \\
\text { evaluación entre pares y socialización en plenaria. } \\
\text { IE1.3 ¿En mi docencia, qué tan conectivista, constructivista, } \\
\text { cognitivista y/o conductista soy? ¿Qué enfoque o combinación de } \\
\text { enfoques educativos uso? ¿Por qué? Dar ejemplos. Habrá co- } \\
\text { evaluación y socialización en plenaria }\end{array}$ \\
\hline $\begin{array}{l}\text { Recursos de base para } \\
\text { el aprendizaje }\end{array}$ & $\begin{array}{l}\text { Para RO1, IE1.1 e IE1.3: Galvis, ÁH (2010). Nuevos ambientes } \\
\text { educativos basados en tecnología. } \\
\text { Para RO1, IE1.2 e IE1.3: Galvis, ÁH (2012) Teorías de } \\
\text { aprendizaje como sustento a la creación de AVAs. }\end{array}$ \\
\hline
\end{tabular}




\section{Apéndice 3. Diseño educativo del Seminario de Didáctica Aplicada - Nivel 2}

\begin{tabular}{|c|c|}
\hline $\begin{array}{l}\text { Gran idea } 2 \text { (GI2) / } \\
\text { Concepto fundamental } \\
\text { que debe perdurar en el } \\
\text { tiempo }\end{array}$ & $\begin{array}{l}\text { GI2. El diseño de cursos bajo enfoque de grandes ideas se lleva a } \\
\text { cabo especificando el para qué y qué enseñar, luego el qué tan } \\
\text { bien y cómo demostrar lo aprendido, y finalmente, cómo llegar al } \\
\text { conocimiento y con qué hacerlo. }\end{array}$ \\
\hline $\begin{array}{l}\text { Resultado observable } 2 \\
\text { / lo que el estudiante } \\
\text { entrega para evaluar }\end{array}$ & $\begin{array}{l}\text { RO2. Al finalizar las actividades de este seminario cada quien } \\
\text { presentará: (1) el diseño global de un curso de su interés y (2) el } \\
\text { diseño detallado de una de sus unidades de aprendizaje. Se } \\
\text { aceptará si lo hecho aplica con propiedad los conceptos que } \\
\text { subyacen a la metodología en estudio. }\end{array}$ \\
\hline $\begin{array}{l}\text { Sistema de evaluación } \\
\text { de los aprendizajes }\end{array}$ & $\begin{array}{l}\text { Se usará rúbrica } 2 \text { para auto-evaluar, co-evaluar y hetero-evaluar } \\
\text { el diseño del RO2. Valores relativos: } 15 \% \text { diseño global, } 30 \% \\
\text { diseño de unidad. Co-evaluación: } 5 \% \\
\text { Se usará la rúbrica TIGRE (Galvis, 2007) para valorar aportes } \\
\text { originales y colaborativos en foros virtuales para discutir IE } 2.1 \text { e } \\
\text { IE 2.2. Aportes originales } 20 \% \text {, aportes colaborativos } 30 \% \text {. Bono } \\
\text { de } 2 \% \text { por mapa mental para fundamentar aportes originales. }\end{array}$ \\
\hline $\begin{array}{l}\text { Interrogantes } \\
\text { esenciales (IE1.x, } x=1 \text {, } \\
\text { 2) / andamios para llegar } \\
\text { al conocimiento }\end{array}$ & $\begin{array}{l}\text { IE2.1 ¿Por qué y qué enseñar en un curso (re)diseñado por } \\
\text { grandes ideas?, ¿cómo demostrar que se aprendió?, ¿con qué } \\
\text { estrategia debería enseñarse dicho curso? } \\
\text { IE2.2 ¿Cómo se debe diseñar cada una de las unidades de } \\
\text { aprendizaje en un curso que se (re)diseña por grandes ideas, con } \\
\text { pedagogía activa y uso de tecnologías digitales? }\end{array}$ \\
\hline $\begin{array}{l}\text { Recursos de base para } \\
\text { el aprendizaje }\end{array}$ & $\begin{array}{l}\text { Para RO2: Galvis, ÁH (2017) Formatos para diseño de cursos por } \\
\text { grandes ideas, con pedagogía activa y usando tecnología. } \\
\text { Para RO2, IE2.1 e IE2.2: Galvis, ÁH y Pedraza, LC (2012). } \\
\text { Rediseño de cursos para la comprensión de grandes ideas e } \\
\text { integración de tecnologías para el aprendizaje } \\
\text { Para participación en foros IE2.1 e IE2.2: Galvis, ÁH (2007) } \\
\text { TIGRE y TGRE, dos caras de la rúbrica para valorar aportes en } \\
\text { discusiones pragmáticas. }\end{array}$ \\
\hline
\end{tabular}




\section{Referencias}

Aarón, M. A., Choles, P., \& Cuesta, R. (2017). Reflexiones acerca de la MPTIC-Maestría en Pedagogía de las TIC - desde las perspectivas estratégica y táctica. Congreso Internacional de Ciencia y Tecnología CIETYC Uniguajira (págs. 1-10). Riohacha: Universidad de la Guajira.

Ander-Egg, E. (2003). Repensando la Investigación-acción participativa. Lumen-Humanitas. Obtenido de https://goo.gl/nXvvgG

Bates, A. W. (2015). Teaching in a Digital Age - Guidelines for designing teaching and learning. Vancouver, Canada: British Columbia University: Open Text. Recuperado el 04 de 2016, de https://opentextbc.ca/teachinginadigitalage/

Collison, G., Elbaum, B., Haavind, S., \& Tinker, R. F. (2002). Facilitating online learning: effective strategies for online facilitators. Madison, WI: Atwood Publishing.

Churches, A. (2008). Taxonomia de Bloom para la era digital. . Recuperado el 7 de abril de 2017, de Eduteca: http://www.eduteka.org/TaxonomiaBloomDigital.php

Flores, M. D., \& García, E. O. (2011). Nuevo modelo educativo, mismos docentes. Tiempo de Educar, 12(23), págs. 29-46.

Forté, E., \& Wentland, M. (1998). The ARIADNE project: knowledge pools for computer-based and telematics supported classical, open and distance education. AAUC Ariadne Academic Users Group Conference (págs. 1-23). Lucerna, Swtizerland: AAUC.

Galvis, Á. H. (2007). Criterios y rúbrica TIGRE para autocontrolar calidad de aportes en discusiones. Bogotá: Metacursos, SAS. Recuperado el 27 de abril de 2017, de http://aportetigre.blogspot.com

Galvis, Á. H. (diciembre de 2010). Nuevos ambientes educativos basados en tecnología. Revista Sistemas, 117, págs. 12-21. Recuperado el 24 de enero de 2016, de https://goo.gl/Y9jkM1

Galvis, Á. H. (5 de marzo de 2012). Teorías de aprendizaje como sustento a la creación de AVAs. Bogotá, DC: Metacursos SAS. Recuperado el 24 de enero de 2016, de https://goo.gl/fUcUa0

Galvis, Á. H. (2017A). AHA, más allá de APA con AVA, donde las mezclas deben ser multidimensionales. En P. Ávila Muñoz, \& C. Rama Vitale (Edits.). México: INFOTEC VIRTUAL EDUCA. Recuperado el 04 de 2017, de https://www.infotec.mx/es_mx/infotec/libros_electronicos

Galvis, Á. H. (2017B). Documentación de casos institucionales de buenas prácticas en bLearning y/o eLearning en educación superior. Bogotá, DC: Uniandes - ConectaTE: Anexo 4 de Informe final a Colciencias proyecto "Desarrollo y validación de una metodología para la generación sostenible de programas educativos en la modalidad Blended Learning" (manuscrito).

Galvis, Á. H., \& Pedraza, L. C. (julio-diciembre de 2012). Rediseño de cursos para la comprensión de grandes ideas e integración de tenologías para el aprendizaje. EDUWEB - Revista de Tecnología de Información y Comunicación en Educación, 6(2), págs. 13-47. Recuperado el 12 de abril de 2016, de http://servicio.bc.uc.edu.ve/educacion/eduweb/vol6n2/art1.pdf

Galvis, Á. H., \& Pedraza, L. C. (2013). Desafíos del eLearning y del bLearning en Educación Superior. En N. Arboleda Toro, \& C. Rama Vitale (Edits.), La educación superior a distancia y virtual en Colombia: Nuevas realidades (págs. 113-154). Bogotá, DC: Virtual Educa y ACESAD.

Garcés-Prettel, M., Ruiz-Cantillo, R., \& Martínez Ávila, D. (2014). Transformación pedagógica mediada por tecnologías de la información y la comunicación (TIC). Saber, Ciencia y Libertad, 9(2), págs. 217-228. Obtenido de https://dialnet.unirioja.es/descarga/articulo/5104968.pdf

Ghiso, A. (1999). Prácticas generadoras de saber. Reflexiones frereirianas en torno a las claves de la sistematización. Recuperado el 7 de abril de 2017, de DICOM - Universidad Católica Luis Amigó: https://goo.gl/ejBmGT

González García, V. (2005). Tecnología digital: reflexiones pedagógicas y socioculturales. Revista Actualidades Investigativas en Educación, 5(1). doi:https://doi.org/10.15517/aie.v5i1.9121

Gonzalvez Aaron, M. A. (2016). El contexto, elemento de análisis para enseñar. Zona Próxima, (25), 3448. doi:http://dx.doi.org/10.14482/zp.25.9790 
RED. Revista de Educación a Distancia, Núm. 58. Artíc. 2

DOI: http://dx.doi.org/10.6018/red/58/2 http://www.um.es/ead/red/58/galvis_et_al.pdf

Graffe, G. J. (2006). La Planificación, modalidades y el uso de modelos. Universidad Central de Venezuela. Caracas: Departamento de Pensamiento Social y Proyectos Educativos. Recuperado el 20 de 01 de 2018, de https://goo.gl/sUZEiC

ITESM. (octubre de 2014). Aprendizaje invertido. Monterrey, NL, México: ITESM - Observatorio de Innovación Educativa. Recuperado el 04 de 2017, de http://www.observatorioedu.com/edutrendsaprendizajeinvertido

ITESM. (25 de 9 de 2017). Glosario de innovación educativa. Recuperado el 10 de 10 de 2017, de Observatorio de Innovación Educativa: https://observatorio.itesm.mx/edunews/2017/9/25/glosario-de-innovacin-educativa

ITSON EAD. (sin fecha). Glosario. Obtenido de Instituto Tecnologico de Sonora - Coordinación de Educación a Distancia: http://www.itson.mx/servicios/adistancia/Documents/glosario_EAD.pdf

Lewin, K. (1939). Force field analysis. En J. P. Jones (Ed.), Group Facilitators. La Jolla, CA: University Associates.

López, Y., \& Martinez, B. (Septiembre-diciembre de 2016). Integración de las TIC en el aprendizaje del proceso administrativo. Omnia Universidad del Zulia, 22(3), 26-45. Recuperado el 6 de abril de 2017, de http://www.redalyc.org/articulo.oa?id=73752819003

Lozada, J. (diciembre de 2014). Investigación aplicada: Definición, propiedad intelectual e industria. CIENCIAMÉRICA, págs. 34-39. Obtenido de https://goo.gl/12dAL1

Martínez Ruiz, M. Á., \& Sauleda Parés, N. (2006). Las universidades en la era numérica: Nuevas tecnologías, nuevos problemas, nuevas teoría. En V. Carrasco Embuena, \& M. Á. Martínez Ruiz (Edits.), La construcción colegiada del modelo docente universitario del siglo XXI (Vol. 1). Universidad de Alicante: Editorial Marfil.

Mitchell, I., Keast, S., Panizzon, D., \& Mitchell, J. (abril de 2017). Using 'big ideas' to enhance teaching and student learning. Teachers and Teaching - Theory and practice. doi:https://doi.org/10.1080/13540602.2016.1218328

OPS OMS. (sin fecha). Glosario general. Recuperado el 15 de 09 de 2017, de Curso virtual: Diseño de programas educativos y materiales didácticos para aprendizaje en la red: https://cursos.campusvirtualsp.org/mod/glossary/view.php?id=1242

Osorio Gómez, L. A. (2011). Interacción en ambientes híbridos de aprendizaje: Metáfora del contínuum. Barcelona: Editorial UOC.

Osorio Gómez, L. A., \& Duart, J. M. (2012). A hybrid approach to university subject learning activities. British Journal of Educational Technology, 43(2), págs. 259-271. doi:10.1111/j.14678535.2011.01175.x

Peralta Caballero, A., \& Diaz-Barriga Arceo, F. (2010). Diseño instruccional de ambientes virtuales de aprendizaje desde una perspectiva constructivista. México, DF: Manuscrito. Recuperado el 23 de noviembre de 2017, de https://goo.gl/fmjPeS

Pérez Serrano, M. (30 de abril de 2006). Rol docente y pedagogía activa en la formación universitaria. La enseñanza centrada en el aprendizaje del alumno. Adaptación del programa al EEES. Recuperado el 20 de noviembre de 2017, de Buleria - Repositorio Institucional Abierto: http://buleria.unileon.es/xmlui/handle/10612/3244

Restrepo Gómez, B. (2004). La investigación-acción educativa y la construcción de saber pedagógico. Educación y Educadores(7), págs. 45-55. Recuperado el 27 de 12 de 2017, de http://www.redalyc.org/pdf/834/83400706.pdf

Restrepo Gómez, B., Puerta, M. V., Perdomo, E., Moreno, L., Hincapié, Z., \& Méndez, A. (2011). Casos de investigación-acción educativa. En C. E. Solidaria (Ed.), Investigación-Acción Pedagógica (págs. 139-295). Medellín.

Rossett, A., \& Frasee, R. V. (2006). Blended learning opportunities. Obtenido de Researchgate: http://www.researchgate.net/publication/228669485_Blended_Learning_Opportunities

Aprendiendo de una transformación de prácticas pedagógicas en cursos de maestría en la modalidad híbrida de aprendizaje. Álvaro Hernán Galvis, Yelenis Yanit López González y Marlín Alicia Aarón Gonzálvez. 
RED. Revista de Educación a Distancia, Núm. 58. Artíc. 2

Sáez Vacas, F., García, O., Palao, J., \& Rojo, P. (s.f.). Glosario. Recuperado el 20 de diciembre de 2017, de Innovación tecnológica en las empresas: http://dit.upm.es/ fsaez/intl/capitulos/Glosario.pdf

Sáez Vacas, F., García, O., Palao, J., \& Rojo, P. (sin fecha). Glosario. Recuperado el 09 de 2017, de Innovación tecnológica en las empresas: http://dit.upm.es/ fsaez/intl/capitulos/Glosario.pdf

Santos, D. (8 de 11 de 2013). Glosario de términos educativos para el docente digital. Obtenido de GoConqr: https://www.goconqr.com/es/examtime/blog/glosario-de-terminos-educativos/

The National Center for Academic Transformation. (2005). Who we are. Recuperado el 21 de septiembre de 2017, de The National Center for Academic Transformation: http://www.thencat.org/whoweare.html

UNESCO. (2011). Alfabetización mediática e informacional. Curriculum para profesores. (A. Grizzle, \& C. WIlson, Edits.) Recuperado el 15 de 09 de 2017, de UnescoDoc: http://unesdoc.unesco.org/images/0021/002160/216099S.pdf

UNESCO. (2011). Alfabetización mediática e informacional. Curriculum para profesores. UNESCODOC. Recuperado el 20 de diciembre de 2017, de http://unesdoc.unesco.org/images/0021/002160/216099S.pdf

UNIGUAJIRA - MOTIVAR. (2010). Documento Base Maestría en Pedagogía de las TIC. Riohacha: Universidad de La Guajira, Grupo Motivar (Manuscrito).

UNIGUAJIRA - MPTIC. (2011). Orientaciones pedagógicas de la MPTIC. Riohacha: Autor: Mimeografiado.

Vallejo, A. P., \& Montes, A. H. (2010). Integración de las TIC en la asignatura de Tecnología de Educación Secundaria . Píxel-Bit. Revista de medios y educación(37), págs. 225-237.

Wiggins, G., \& McTighe, J. (2001). Undestanding by design. Upper Saddle River, NJ: Merril Prentice Hall.

Wiggins, G., \& McTighe, J. (2005). Understanding by Design. (2). Alexandria, VA, USA: ASCD. Recuperado el 09 de 2017, de http://ecosensing.org/wp-content/uploads/2015/11/Understandingby-Design-Expanded-2nd-Edition.pdf

Aprendiendo de una transformación de prácticas pedagógicas en cursos de maestría en la modalidad híbrida de aprendizaje. Álvaro Hernán Galvis, Yelenis Yanit López González y Marlín Alicia Aarón Gonzálvez. 